\title{
Organising and Launching a Scholarly Open Access Journal
}

\author{
Peter Berkesand \\ Linköping University Library \\ Linköping University Electronic Press
}




\section{Organising and Launching a Scholarly Open Access Journal}

Peter Berkesand

Linköping University Library

Linköping University Electronic Press 
Title: Organising and Launching a Scholarly Open Access Journal Author: Peter Berkesand

Published by: Linköping University Electronic Press, 2021

ISBN: 978-91-7929-649-0

DOI: https://doi.org/10.3384/9789179296490

(C) Peter Berkesand

(c) (i)

Attribution 4.0 International (CC BY 4.0). 


\section{Table of Contents}

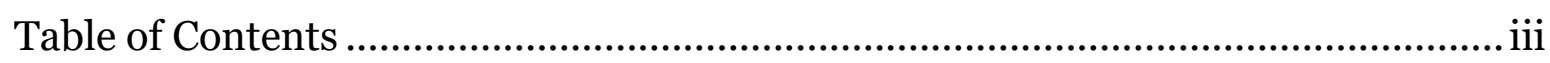

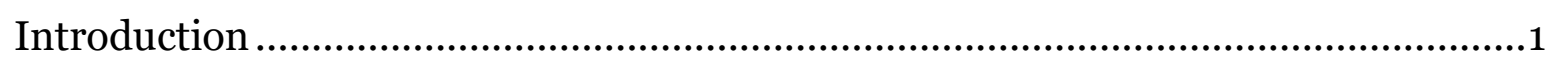

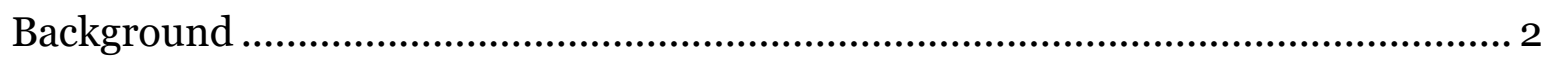

Checklist ....................................................................................................... 4

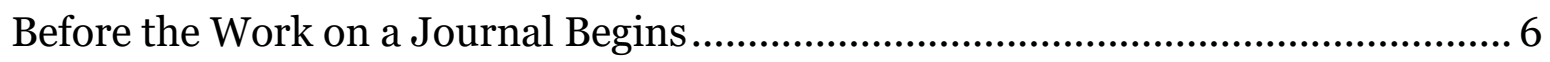

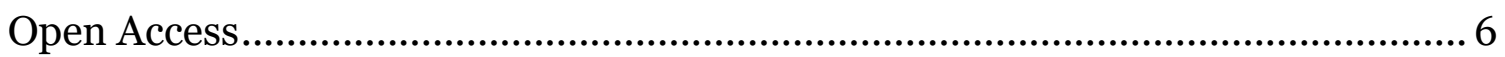

Is there a Need for a New Journal?.................................................................. 7

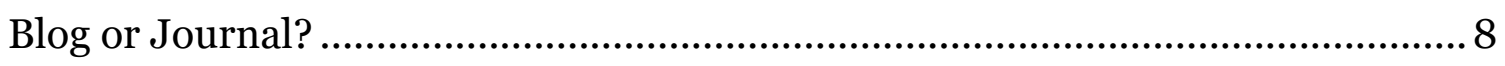

Converting an Existing Journal to Open Access.................................................... 8

Hosting the Journal ............................................................................................ 9

Support System for Electronic Publishing........................................................... 9

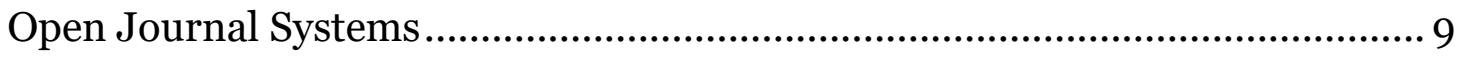

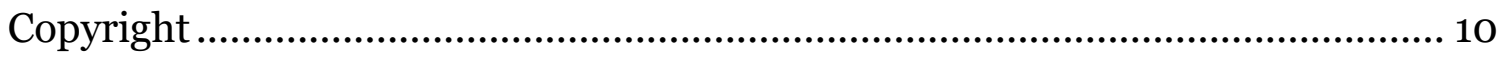

Permission to reuse published material.......................................................... 10

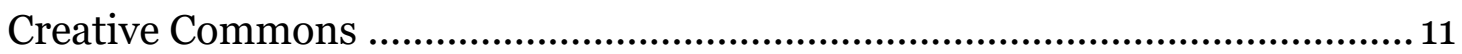

General Data Protection Regulation...............................................................12

Persistent Links ..............................................................................................

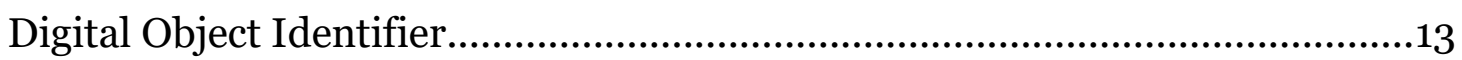

The Construction of a DOI............................................................................

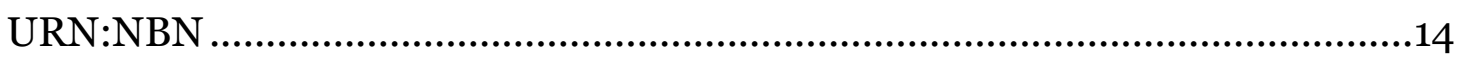

The Construction of an URN:NBN …………………….............................15

Refer to a Journal Article with a Persistent Link .................................................15

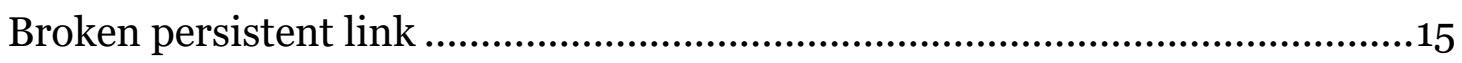

International Standard Serial Number, ISSN ................................................16

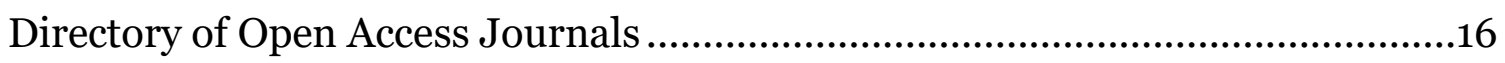

Correct Affiliation ..............................................................................................

Open Researcher \& Contributor ID ..................................................................17

The construction of ORCID ............................................................................17

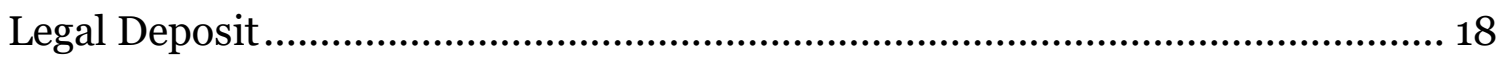

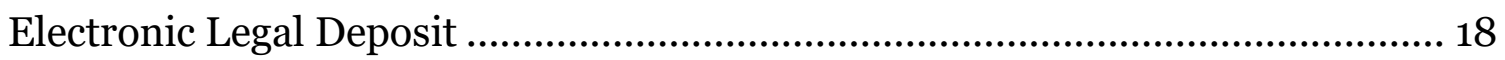

Organise the Journal and the Administration .........................................................19

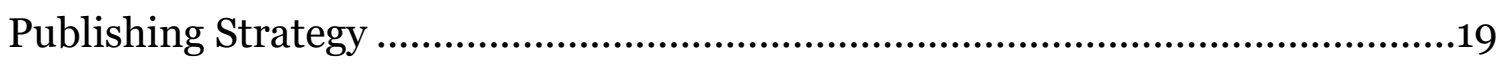

Publishing Frequency and Method ................................................................19

Economic Plan................................................................................................19

Economic and Scientific Support ..................................................................20

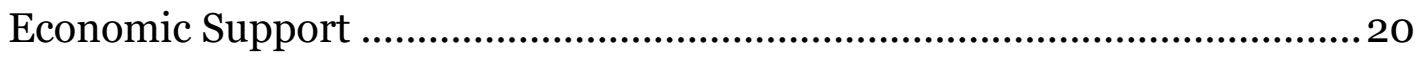


Support from the Department at the University .......................................20

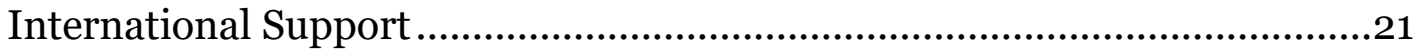

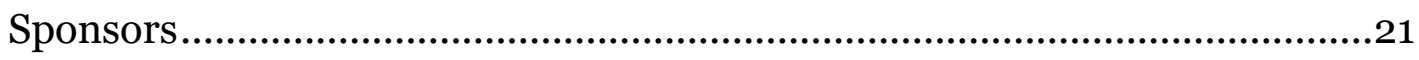

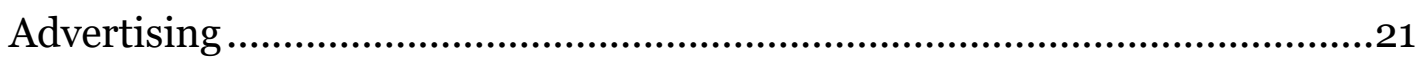

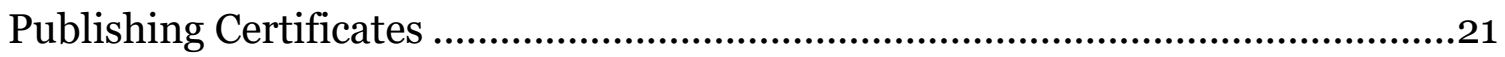

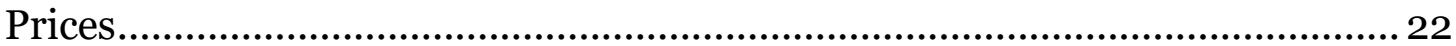

Editorial Office or Editorial Team ............................................................... 22

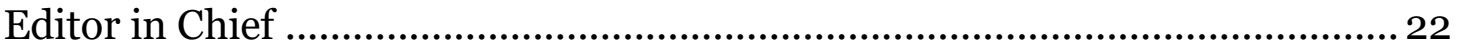

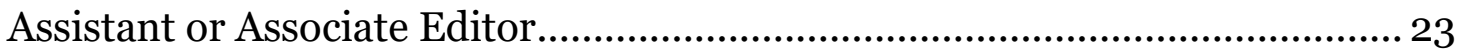

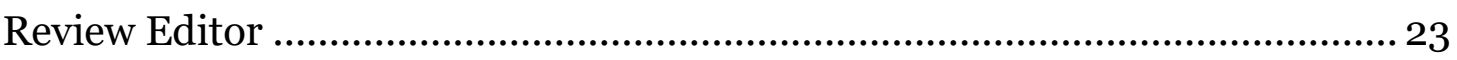

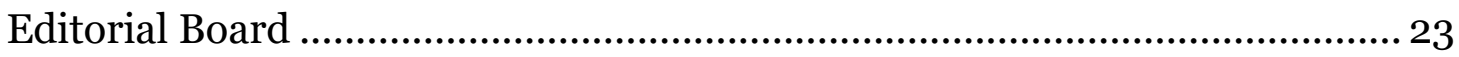

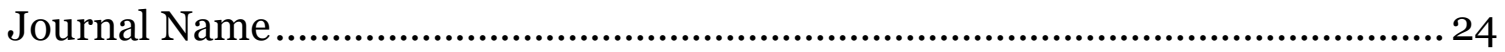

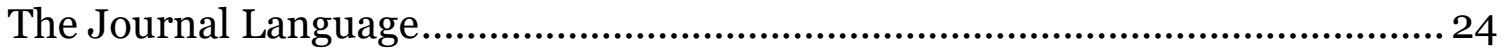

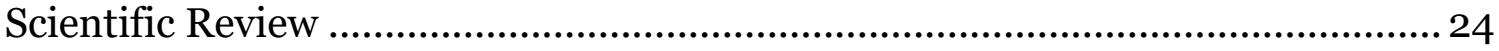

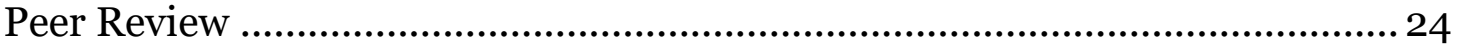

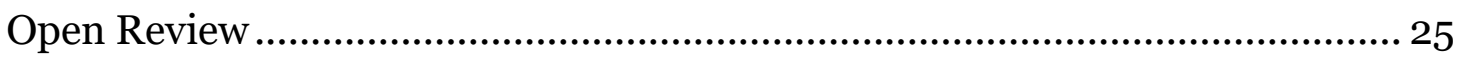

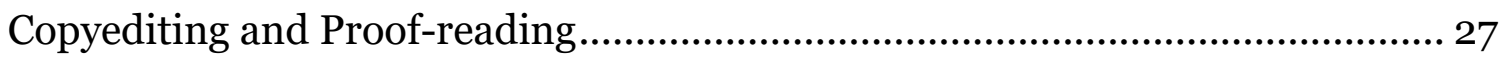

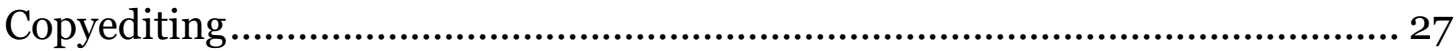

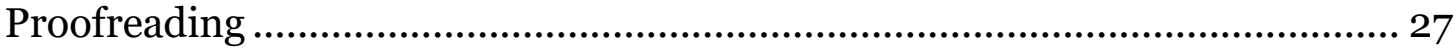

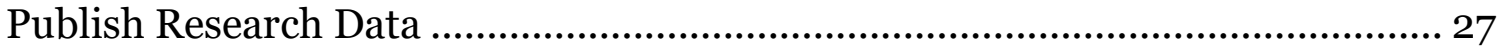

Why Publish Research Data? .................................................................. 28

Publishing Agreement and Terms .............................................................28

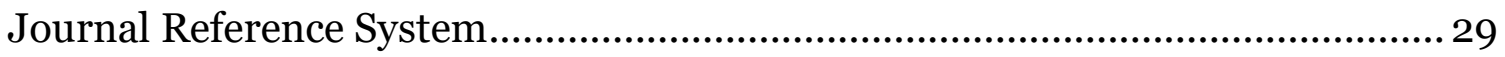

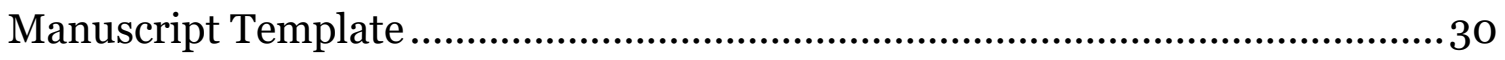

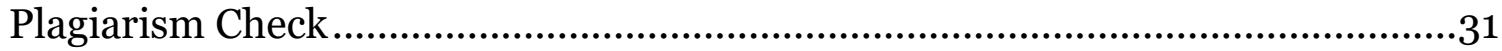

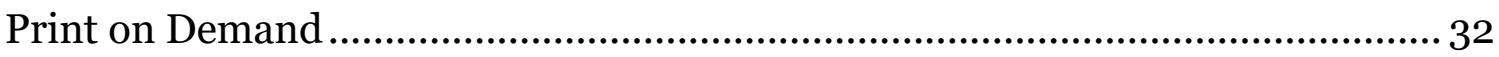

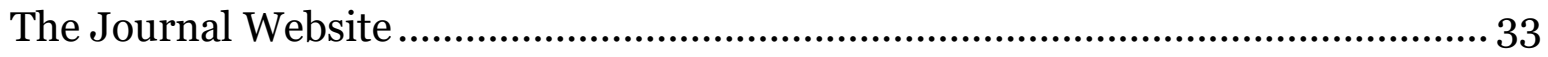

Accessibility of the Websites and Mobile Applications ....................................... 33

Design and Publish the Journal's Website ......................................................... 33

Adapt the Website for Mobile Phone Use ............................................................ 34

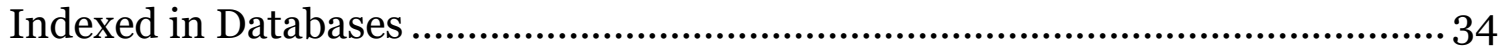

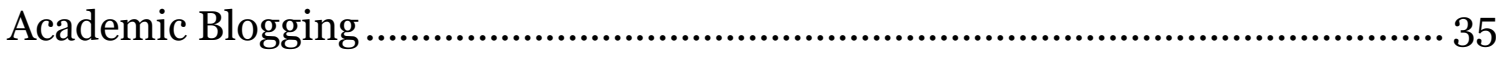

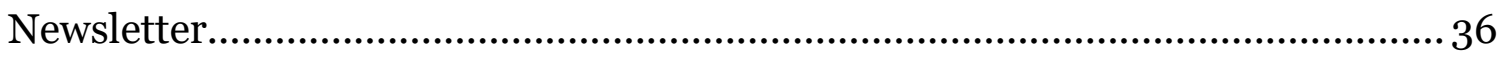

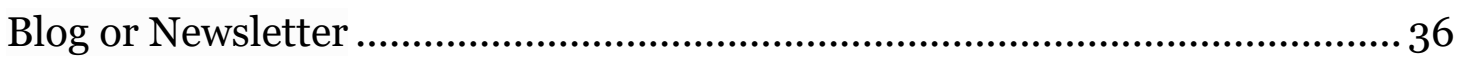

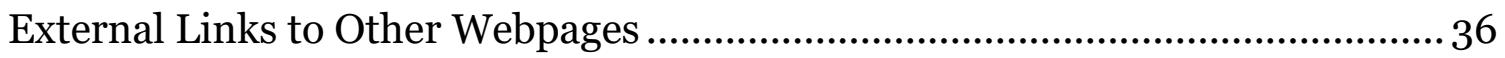

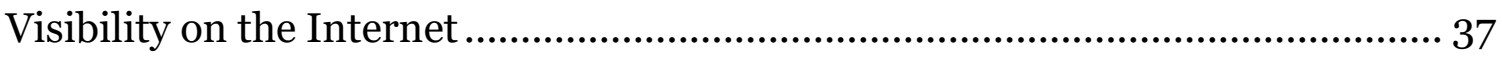

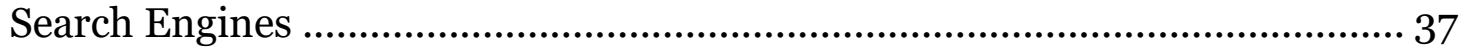




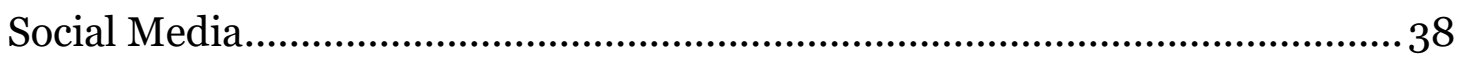

Altmetrics............................................................................................... 39

Social Media and Persistent Links............................................................. 39

Scholarly networks.................................................................................... 39

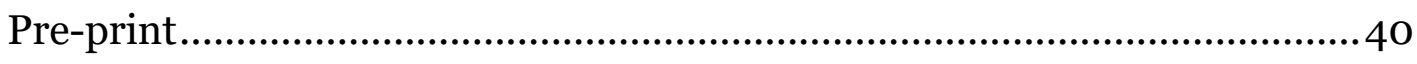

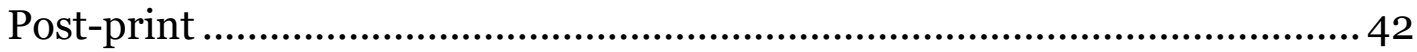

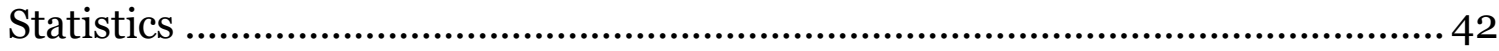

Acknowledgement .......................................................................................... 44

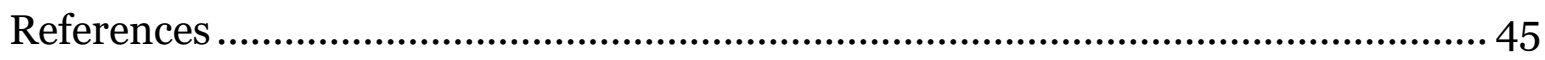




\section{Introduction}

This essay should be read as a guide for researchers or prospective editors, how to best organise and launch a scholarly open access journal from idea to publication of the first volume and issue. The essay addresses various subjects important for publishing and provides suggestions and explanations of various available services, tools, resources, organisations or other stakeholders which can be very useful when working with the new journal. The essay does not claim to be comprehensive in the subject but should be seen as a well-prepared manual mainly based on my own experiences as a former editor at Linköping University Electronic Press (LiU EPress), ${ }^{1}$ where I assisted and supported researchers launching a number of open access journals hosted by LiU E-Press and publishing journal articles. The writing is mainly aimed at a Swedish audience but of course works for other countries as well.

I have deliberately avoided referring to blogs and unofficial websites because links to these pages tend to stop working after a few years. There are a lot of good blogs with essential information on how to start a journal. Use a search engine to search for more information.

1 Linköping University Electronic Press. 2020. http://www.ep.liu.se (Accessed June 22 ${ }^{\text {nd }}$ 2020). 


\section{Background}

Cheap and more powerful computers in combination with the breakthrough of the Internet in the mid-1990s, was a major asset for social development in general and for communication and information dissemination in particular. The Internet gave the possibility to create web pages for electronic publishing and it became easy to disseminate information about governments, authorities, companies, universities, municipalities and organisations and for communication in general. Sending messages and attaching files with the message also was a huge step for quick and effective communication. The Internet meant a near revolution.

The Internet also meant that commercial publishers, publishing scientific journals, could easily publish their journals electronically and not in printed form only. This development took some time and did not take-off until sometime in the beginning of the 200os, when journals were available both in printed and electronic versions. A contributing reason for the increase in electronically published journals was the possibility for:

- Searching articles within the journal or the publisher's journals.

- Articles that are always available.

- not having to visit the University library for a printed copy.

- e-mailing authors or editors with comments

- publishing audio and video files and other kinds of graphics which were (and still are) easy to embed in journal articles' html pages or in a pdf file. ${ }^{2}$

Today, there are still both printed and electronic journals available for various reasons such as libraries and researchers who want/prefer a printed copy, selfarchiving the printed journal at the library and, of course, tradition. But the electronic version is more common for economic reasons and printed version are becoming rather rare nowadays.

It has for a long time been a tradition with a system whereby researchers at universities and colleges, via a Copyright Transfer Agreement 3 , transfer their copyright to the commercial publishers and individual journals. Through expensive subscriptions, universities and research institutes are forced to buy back articles through their libraries so that researchers can access research results funded by both public and private research funds. As if that were not enough, researchers are often asked to review manuscripts for free before a manuscript is accepted for publication by a journal. The cost of subscriptions is very high and burdens a large part of a library's budget. As a counter-reaction to these high costs, an open access movement was initiated which means that scientific research articles should be freely published on the Internet and in 1991 the physicist Paul Ginsberg started ArXiv.org. 4 ArXiv.org is an open access pre-print archive where academic researchers can publish their articles electronically free of charge. Several Swedish research funds, including the

2 Trajkovski, V. Editorial. A Comparison Between Electronic and Printed Journals. Journal for ReAttach Therapy and Developmental Diversities, 1(1) 2018: 1-6.

https://doi.org/10.26407/2018JRTDD.1.1.

3 Copyright Transfer Agreement. Wikipedia. 2020

https://en.wikipedia.org/w/index.php?title=Copyright transfer agreement\&oldid $=934181894$ (Accessed March 23 ${ }^{\text {rd } 2020) . ~}$

4 History of the Open Access Movement. Open Access. Der freie Zugang zu wissenschaftlicher Information. 2020. https://open-access.net/en/information-on-open-access/history-of-theopen-access-movement (Accessed February $1^{\text {st }}$ 2020) ArXiv.org. 2020. https://arxiv.org/about (Accessed February $1^{\text {st }}$ 2020). 
Swedish Research Council (VR) and the Research Council for Health, Work and Welfare (FORTE) 5 , require research funded to be published open access ${ }^{6}$ The European Union's Horizon $2 \mathrm{O}^{7} \mathrm{O}^{7}$ research program also requires scientific research funded by them to be published open access.

Commercial publishers, which can be open access, compete with each other as they publish several journals within the same research areas. This competition has been addressed by several open access journals which, instead of demanding a subscription fee, charge an author fee, Article Processing Charge (APC), which can be very high. ${ }^{8}$ In order to avoid becoming dependent on subscription fees from commercial publishers, researchers at various universities and research institutes have themselves initiated open access journals that charge author fees that are significantly lower. In Sweden, several journals have been founded by researchers who, instead of raising author fees, are financed by research funds. 9

For today's researchers, visibility in their research area within the research community is more or less crucial. Social and scientific networks have become a great asset for researchers to disseminate their publications. This visibility and contact network, often leads to increased citation of published articles. ${ }^{10}$ Researchers' publications should gain dissemination and be available to as large a readership as possible and preferably it should cost nothing to the reader to take part of the research. For this to be possible without high costs, open access publishing is required.

$5 \quad$ FORTE. Policy for Publication with Open Access. FORTE, 2020. https://forte.se/en/funding/ongoing-grants/plan-s-open-access/policy-publication-open-access/ (Accessed April 12 $2^{\text {th }}$ 2020).

6 Swedish Research Council [Vetenskapsrådet]. Förslag till Nationella riktlinjer för öppen tillgång till vetenskaplig information, Vetenskapsrådets rapporter 2015.

7 European Commission. What is Horizon 2020? 2020.

https://ec.europa.eu/programmes/horizon2020/what-horizon-2020 (Accessed April 12 ${ }^{\text {th }}$ 2020); European Commission. Open Science (Open Access). 2020. https://ec.europa.eu/programmes/horizon2020/en/h2020-section/open-science-open-access (Accessed April 12 ${ }^{\text {th }}$ 2020); OpenAIRE. 2020. https://www.openaire.eu/ (Accessed April $12^{\text {th }}$ 2020).

8 Article Processing Charge (APC). Wikipedia. 2020. https://en.wikipedia.org/w/index.php?title=Article processing charge\&oldid=948486566 (Accessed March $19^{\text {th }}$ 2020).

9 Linköping University Electronic Press. Journals. 2020. https://ep.liu.se/en/journals.aspx (Accessed April 12 $2^{\text {th }}$ 2020); Lund University, Open Access Journals at Lund University. 2020. https://journals.lub.lu.se/ (Accessed April 12 ${ }^{\text {th }}$ 2020).

10 Yang Li, Chaojiang Wu, Erjia Yan \& Kai Li. Will open access increase journal CiteScores? An empirical investigation over multiple disciplines, Plos One, 13(8), 2018: e0201885 https://doi.org/10.1371/journal.pone.0201885; Rodrigo Costas, Zohreh Zahedi and Paul Wouter. The thematic orientation of publications mentioned on social media: Large-scale disciplinary comparison of social media metrics with citations, Aslib Journal of Information Management, 67(3), (2015), https://doi.org/10.1108/AJIM-12-2014-0173. 


\section{Checklist}

Starting a new scholarly journal can be intimidating because of all the decisions and considerations that has to be made before publishing the first issue. Below is a checklist with best-practice and quick guidelines what it takes setting up an Open Access scholarly journal. The contents of the checklist will be discussed in more detail in the publication.

- Open Access. Decide under which type of open access the journal to be published under: Green open access, Gold open access or Diamond open access.

- Hosting the Journal. The journal must be hosted on a secure a professionally managed server with a domain name.

- Support System for Electronic Publishing. To facilitate the publishing of the journal an editorial support system can be used such as the most common Open Journal Systems (OJS).

- Copyright. When publishing an article, it is important that the author and journal does not infringe the copyright protected material. It is also important to decide whether the author should retain the copyright or whether it should be transferred to the publisher. Creative commons are used by many journals telling the user what to do or not to do with the article contents.

- Persistent Links. Stable links to an article is important for the journal and the published article. The most used system is Digital Object Identifier (DOI) and is crucial in order to get citations statistics for the articles.

- International Standard Serial Number (ISSN). The purpose with ISSN system is to numbering periodicals such as scientific journals and identify the periodicals. In Sweden, an application for ISSN can be sent to the National Library of Sweden (KB), when the journal has published its first volume/issue.

- Directory of Open Access Journals (DOAJ). DOAJ is an international independent databased which contains quality open access journals and very important for open access journals.

- Legal Deposit. Almost all countries have a legal deposit archive for printed and e-published material and the journal should send copies to the country legal deposit archive.

- Organise the Journal and the Administration. The administration decides and handle the Publishing Strategy containing Publishing Frequency and Method and have an Economic Plan for the journal.

- Editorial Office or Editorial Team. The journal must have an Editor in Chief, Assistant or Associate Editor and many journals also have a Review Editor. An Editorial Board is absolutely crucial for the journal's survival and credibility.

- Journal Name. The journal name should reflect the research area and have a descriptive title. The journal title should not have a name that could mixed with already existing journals. Decide which language the journal should use.

- Copyediting and Proof-reading. A manuscript, submitted to the journal, must undergo copyediting and proof-reading to check for grammar and spelling errors etc.

- Scientific Review. A submitted manuscript to the journal must absolutely undergo a scientific peer-review process in order to maintain a high scientific standard. 
- Publishing Agreement and Terms. An agreement between the journal host is necessary and an agreement between the journal and the author(s) is very important in order to avoid any legal disputes.

- Manuscript Template. To avoid a lot of work formatting the submitted manuscript, use a template which can be downloaded from the journal website by the author(s). A well prepared template will also facilitate the process of making the article file accessible for people with reading disabilities.

- Plagiarism Check. Copying other authors work is a problem. To avoid plagiarism, use a plagiarism check system.

- The Journal Website is crucial and very important for the journal. The website should contain information about the journal Aim \& Scope, Submission guidelines, Policies \& ethics, Editorial board, Newsletter etc.

- Indexed in Databases. There are a number of scientific databases a journal should be indexed in, in order to increase the journal credibility and visibility.

- Visibility on the Internet. An important process is the visibility for the journal on the Internet and the research community. This can be done by applying metadata for each article and pdf files. The visibility also includes social medias, Altmetrics. Scholarly networks are also an important gate to visibility.

- Statistics. Journal statistics should be visible on the journal website. This includes number of visitors, downloaded pdffiles, most cited articles, Altmetrics, citation index etc. 


\section{Before the Work on a Journal Begins}

Organising and launching an open access journal are not a very complicated processes but labour intensive and time-consuming. There are many decisions that need to be made before everything is ready for the launch and the first volume and issue can be published online.

Launching and publishing a journal means that people involved in the project should know and be reasonably familiar with many issues, concepts or various services and tools offered by other actors, which are important in a publishing context. Under the above headings, this information is presented which a journal has great benefit from before it is launched and upon publication as well as the conditions so that a journal is perceived as serious by prospective authors and readers.

\section{Open Access}

Open access is an international and widely accepted term which means that research results are made freely available on the Internet at no cost to the reader. ${ }^{11}$ Open Access can be divided into four different publishing models:

Green Open Access (also called parallel publishing, self-archiving or post-print publishing) enables the researcher to publish the publication via either the researcher's own website or the university's institutional repository. ${ }^{12}$ See also the headline Post-Print on page 15.

Hybrid Open Access means that an author who wants to publish their article in a journal, which normally requires a subscription and publishes behind a "pay wall", can publish the article open access for a fee. This method is very costly for the author but lucrative for the publisher since the publisher charges both for the subscription fee and charges a publishing fee to make the article open access.

Gold Open Access means that there is no subscription fee for a journal but the author pays a fee to have the article published freely available. This fee will cover the costs of the journal (Article Processing Charge, APC). The author retains the copyright and the publication can be published with a Creative Commons license (see the heading Creative Commons).

Diamond Open Access means publishing in a journal that does not charge either a subscription fee or an author fee for publishing an article. All publishing is noncommercial i.e. free. The author retains the copyright to the publication and it is usually published under a Creative Commons license.

In this article, the publishing models Gold Open Access and Diamond Open Access are discussed. ${ }^{13}$

11 Open Access. Wikipedia 2020. https://en.wikipedia.org/w/index.php?title=Open access\&oldid=969970641 (Accessed January $1^{\text {st }}$ 2020).

12 Institutional repository. Wikipedia 2020. https://en.wikipedia.org/w/index.php?title=Institutional repository\&oldid $=951193949$ (Accessed April 25 2020 )

13 Srećko Gajović. Diamond Open Access in the quest for interdisciplinarity and excellence. Croatian Medical Journal, 58(4) 2017: 261-262. https://doi.org/10.3325/cmj.2017.58.261 
The four different publishing models described above are illustrated in Figure 1.14 Depending on the policy of the publisher and the journal, deviations can of course occur.

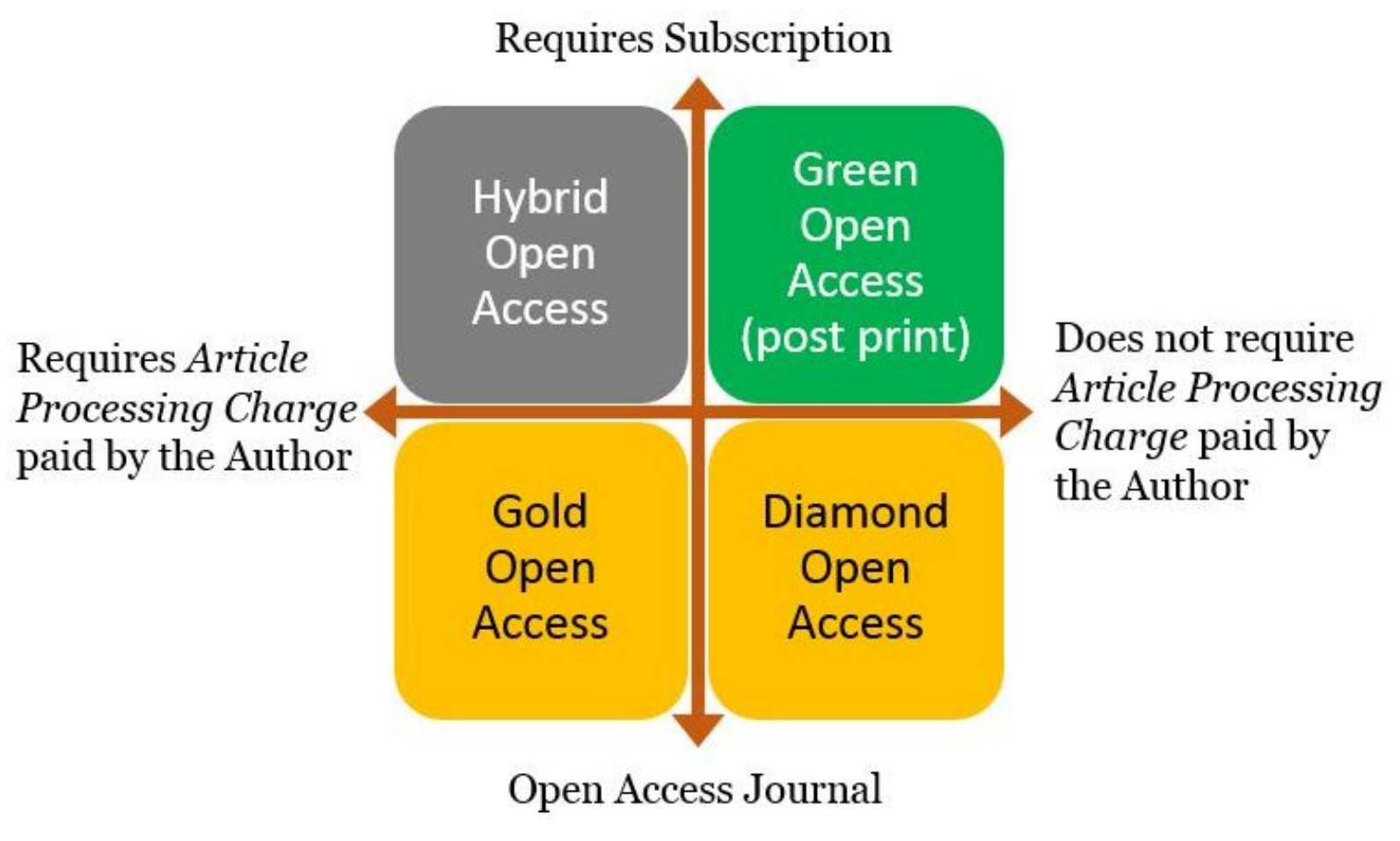

Figure 1. Publishing models for journals. Source: Nählinder, J. (2019) Presentation at the course SCAIRE, Linköping University, October $25^{\text {th }}$ 2019. Translated into English and some text modified by Peter Berkesand

\section{Choose an Open Access Publishing Model}

At an early stage it is important to decide under which open access model a new journal is to be published and how the journal is to be financed as Gold Open Access ${ }^{15}$ with an Article Processing Charge fee (APC) ${ }^{16}$ or as Diamond Open Access completely free of charge for the author and freely available to the reader. It is important for example in the application for membership in the Directory of Open Access Journals ${ }^{17}$ to clearly indicate which Open Access model the journal is published within.

\section{Is there a Need for a New Journal?}

The first question that must be asked is: Is there a need for a new journal within the research area? A new journal should be unique in its kind and improve scholarly information sharing within the research community in the research field the journal will cover, otherwise there is a risk that the journal being out-competed by other existing and already established journals. Make sure that the new journal cannot be absorbed into an already existing journal.

14 Johanna Nählinder, (2020) Presentation at the course SCAIRE, Linköping University, October $25^{\text {th }}$ 2019, PowerPoint-presentation.

15 Open Access. Wikipedia. 2020.

https://en.wikipedia.org/w/index.php?title=Open access\&oldid=969970641 (Accessed April 25 ${ }^{\text {th }}$ 2020).

16 Article Processing Charge. Wikipedia 2020.

https://en.wikipedia.org/w/index.php?title=Article_processing charge\&oldid $=948486566$

(Accessed March 10 ${ }^{\text {th }}$ 2020).

17 See the headline Directory of Open Access Journals. 
Journals covering a broad research area or topic has more opportunity to publish a large number of articles per year. Niche journals within a narrow research area may in the long run be outstripped by already established journals, especially if these are highly regarded in their research area. An analysis of the need for a new journal is therefore important for the future of the new journal and, above all, survival.

One should also discuss which target group that the journal addresses: strictly scientific or popular science content or a target group that are not scientists but work in the school world or in practical professions where scientific facts become an important part of the work.

Another important issue is the journal's survival after it is launched. Those responsible for the journal must ensure that the journal is actually published regularly without interruption in publishing. It is one thing launching a journal but another to maintain publication. The first three to five years are the most intensive when publishing a journal because it takes some time to establish a new open access journal. Ensure that there are staff who can continue to publish the journal and carry on the legacy.

\section{Blog or Journal?}

Note that a blog published as a journal on a University sub domain (a website under the ordinary websites) is not regarded as a journal in Sweden but as a blog. The journal must obtain its own domain name, where the domain name of the university can be part of the journal's domain name. This means that only the journal is published under the journal domain name. An example is the journal International Journal of Aging and Later Life (IJAL) which has domain https://ijal.se/, while the journal Sensorium has an University domain name in its web address https://sensorium.ep.liu.se/. See also the headline Academic Blogging.

Regardless of what type of publication you choose, it is important to clarify from the beginning which target group of readers the journal is aimed at. Should the journal contain popular science articles or be strictly scientific or perhaps both?

\section{Converting an Existing Journal to Open Access}

Most of the subscription commercial publishers and their journals offer open access publishing by author or article fees and these journals are known as hybrid journals. There are journals which are using commercial publishers for hosting and administrating their journals. If the journal is a hybrid journal it might be easier for the journal to convert from hybrid to open access journal and take over the publishing process themselves. This requires negotiating with the publisher (the host) and the journal. The journal must, of course, be an academy-owned journal and not owned by the publisher/host. Instead of starting a new journal it might be a benefit to convert an existing journal to an open access journal:

- The journal has an existing audience i.e. readers.

- The journal has an established academic quality reputation.

- The journal is already indexed in high quality scholarly databases.

- The journal research area is filling a clear academic marketplace.

- The journal has built up an impact factor.

The editorial office/editorial board of the journal are usually the persons who make the decision for converting a journal to open access and will (hopefully) maintain their work after flipping the journal to open access. This means that the journal's 
quality is likely to continue to be high after the conversion of the journal which also sends a clear message to the journal audience that quality publishing will continue as before but with a new publishing host and open access.

\section{Hosting the Journal}

Before the work, building the journal website begins, the journal must be hosted on a secure and professionally managed server with technical support and daily backups of the journal's content. The journal should obtain its own domain name i.e. a URL and have full control of the website and its contents. There are four options:

1. Using an existing commercial host.

2. a University hosts the journal.

3. a Library hosts the journal.

4. Set up and run your own server for hosting the journal.

It has become more and more common that a University or a University Library to host journals. Linköping University launched a publishing house in 1996 with the name Linköping University Electronic Press (LiU E-Press). LiU E-Press is administratively sorted under the University Library. This solution is an option for commercial hosting and at present (July 2020) LiU E-Press hosts 12 open access journals and is using OJS as publishing platform and does not charge any journal for the hosting, DOI and OJS provided that the editors of the journals work at the University or have some kind of connection to the University. This service is also available among other Universities in Europe and North America. ${ }^{18}$

\section{Support System for Electronic Publishing}

In order to facilitate the e-publication of a journal, there are both commercial and free editorial support systems for, among other things. creating a journal's website, handling submitted manuscripts, flow control over the review process until the publication of the articles, sending e-mails etc. ${ }^{19}$ The most common and well-known system among open access journals is Open Journal Systems.

\section{Open Journal Systems}

Open Journal System (OJS) is an Internet-based open source, publishing system for journals developed by the Public Knowledge Project ${ }^{20}$ and helps editors keep track of submitted articles, peer-reviewers etc. up to the time of publication. With OJS it is also possible to create a journal's website and publish all volumes, issues and pdf files online. With OJS, it is easy to improve the access to research result and make it easier to publish scientific journals. Some benefits of OJS:

1. Local installation, operation and administration.

2. The journal website can be published via OJS.

3. Submit manuscripts online.

4. Open, single or "double-blind" peer-review of submitted manuscripts.

18 By Googling the words hosting open access journal a variety of sites will appear for more information.

19 Open Access Directory (OAD). Free and open-source journal management software. 2020. http://oad.simmons.edu/oadwiki/index.php?title=Free and opensource journal management software\&oldid=27461 (Accessed January $22^{\text {nd }} 2020$ )

20 Public Knowledge Project. Open Journal Systems (OJS)., 2020. https://pkp.sfu.ca/ojs/ (Accessed January 22 ${ }^{\text {nd }}$ 2020); Public Knowledge Project. 2020. https://pkp.sfu.ca/ (Accessed January $22^{\text {nd }}$ 2020). 
5. Assign reviewers manuscripts.

6. Complete control over the review process.

7. Handling and administration of all content.

8. Built-in email system.

9. Easy to publish articles online.

10. Automatically assign articles to permanent links such as DOI.

11. Export tools of metadata for depositing DOI to CrossRef.org and metadata to DOAJ.org.

12. Cost effective publishing. The open source code, makes it very easy to produce your own customization and developments of the system.

Open Journal System is an established system used by most quality open access journals not published through commercial publishers and OJS is easy to install, setup and run by using their User Guide. ${ }^{21}$ Linköping University Electronic Press is currently changing over to OJS and all journals will, in due time, be published and accessible via OJS.

\section{Copyright}

Copyright is very important when publishing an article and the content of an article must not infringe any copyright protected material. Knowing at least basic copyright rules is therefore important when publishing. In most countries the copyright is the same for electronically published material as for printed. In Sweden copyright [Upphovsrätt] means that an author owns the right to the work throughout the authors life and after the copyright holder passed away, the copyright passes to the estate and is valid for another 70 years.

The author may enter into agreements where the author writes all or part of the author's copyright to a third party. This procedure is most common when publishing in commercial journals through a Copy Transfer Agreement. The commercial journal usually takes over the economic part of the copyright, but can give the author the right to reuse parts of text as well as figures, photographs, tables, models etc. that are included in the work.

Authors, who publish themselves in an Open-Access journal most often retain the copyright to their work, but exceptions may of course be dependent on how the journal in question defines open access. Open access-published articles usually use a Creative Commons license.

Note that all countries that have signed the Berne Convention ${ }^{22}$ may vary the length of copyright, but will last for at least 50 years after the copyright owner has passed away.

\section{Permission to reuse published material}

The author or authors of a submitted manuscript must ensure that the content of the submitted manuscript does not violate any applicable copyright. If a manuscript

21 User guides, developer documentation and publishing tips for all of the Public Knowledge Project's software. Public Knowledge Project. 2020. https://docs.pkp.sfu.ca/ (Accessed July $25^{\text {th }}$ 2020).

22 Berne Convention. Wikipedia. 2020. https://en.wikipedia.org/w/index.php?title=Berne Convention\&oldid=949417317 (Accessed April $8^{\text {th }}$ 2020). 
contains figures, tables, photographs or other material taken from other, commercially or non-commercially published articles written by other authors and sometimes even their own articles, the authors of the manuscript must obtain permission from the copyright holder to reuse this material. A complete reference must always be given even if you are authorized to reuse the material. There are exceptions if the article is published under a Creative Commons license.

\section{Creative Commons}

Creative Commons (CC)23 is a non-profit organization that was established in 2001. With Creative Commons, a writer of a publication, can decide how the licensing of the work is handled and easily share, all or part of a work such as download, read, copy, distribute, edit or rewrite. Regardless of which CC level one choses, a clear reference to the main source must always be provided. Note that copyright is still owned by the author of the work but the author has decided how the work can be used by other authors. With Creative Commons it is much easier to know what applies and how copyright protected material may be reused.

Creative Commons is based on four blocks:

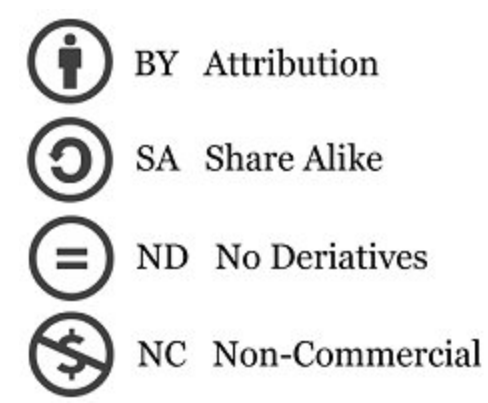

Figure 2. The four Creative Commons blocks.

Image created by Peter Berkesand.

These four blocks can then be combined into six different layers with different rights and presented with a logo (figure 3) on a work's title page as to clearly indicate which level applies.

23 Creative Commons. 2020. http://www.creativecommons.se/ (Accessed February $18^{\text {th }}$ 2020). 

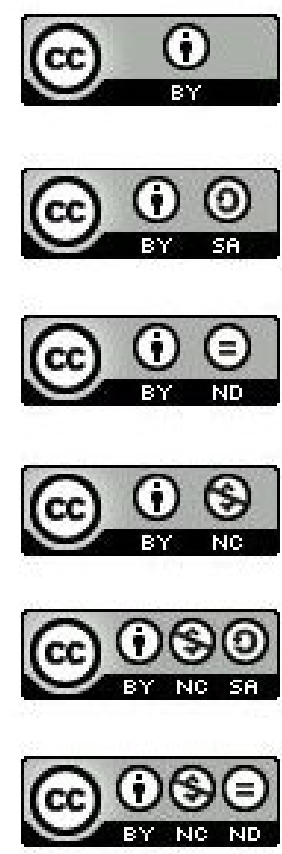

Attribution

CC BY

\section{Attribution-ShareAlike}

CC BY-SA

Attribution-NoDerivs

CC BY-ND

\section{Attribution-NonCommercial}

CC BY-NC

\section{Attribution-NonCommercial-ShareAlike \\ CC BY-NC-SA}

\section{Attribution-NonCommercial-NoDerivs CC BY-NC-ND}

Figure 3. The six different layers. Image created by Peter Berkesand.

Together with the CC logo add text with a link for information how the work is licensed. Example:

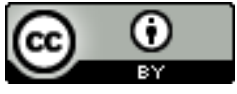

This work is licensed under a Creative Commons Attribution 4.0 International License.

The logo below can be use on a website that is public domain and all material on this particular website, is free to use but with full reference to the website:

\section{PUBLIC
DOMAIN}

Note that a Creative Commons license cannot be revoked for a publication that has been granted a CC license. A licensor, who has specified a work with a Creative Commons license, cannot revoke the license or prevent anyone from using the work within the restrictions of the license. New publishing of the same work can be distributed without a Creative Commons license or with another license, but previous work on the Creative Commons license cannot be revoked.

\section{General Data Protection Regulation}

The General Data Protection Regulation (GDPR) 24 applies since May 25, 2018 throughout EU. The regulation is designed to protect the fundamental rights and freedoms of individuals and in particular the right to the protection of personal data. The regulation does not regulate copyright, but only the processing of personal data.

When publishing a journal, it is inevitable that certain personal information about for example the editors, authors and reviewers are saved in the publishing system OJS. These details are usually first and last name, affiliation, e-mail address, ORCID and

24 General Data Protection Regulation. Wikipedia. 2020.

https://en.wikipedia.org/w/index.php?title $=$ General Data Protection Regulation\&oldid $=95283$ 4870 (Accessed April 26 2020 ). 
login information in OJS such as username and password. How the information is stored and handled should be documented and published on either the publisher's or the journal's website. There must also be very clearly stated whether the publisher or the journal intends to use the information for e.g. statistics or sell the information to third parties. The latter should be avoided because it may harm the journal's credibility.

\section{Persistent Links}

Each article published by a journal or journal publisher should receive a persistent link, also called durable link, deep link, stable link or permanent link, that is stable over time. ${ }^{25}$ It never changes but always looks the same even if the journal and its content change URL or if the full text pdf file changes website. If a publication has a persistent link, always use the persistent link.

\section{Digital Object Identifier}

A system that provides stable links is the Digital Object Identifier (DOI). ${ }^{26}$ DOI is an international system for continuous and reliable identifiers for digital objects. There are several different actors that provide stable links. ${ }^{27}$

The most engaged and best-known organisation is CrossRef.org, ${ }^{28}$ which is a nonprofit organization and operates as an economic association. CrossRef.org offers its members a variety of services that can be used in publishing. Each member pays an annual CrossRef.org membership fee, a fee per DOI and fees for other available services. CrossRef.org is the system that virtually all major publishers of scientific journals use, including LiU E-Press.

A membership of CrossRef.org goes with some legal obligations that must be met:

- All article must have a DOI.

- Make sure that the DOI is only assigned for one article. Never assign the same DOI for two different articles.

- Ensure that DOIs always resolve to the correct landing page i.e. the article metadata page.

- If the host's and URL addresses are moved, the metadata must be updated so the DOI resolves to correct landing page.

- If a reference in the reference list has a DOI add the DOI link in the reference list. This will make it easier for a reader to reach the referenced article.

- Deposit the article metadata and DOI information regularly to CrossRef.org.

CrossRef's Cited-by service helps members find out who is quoting the content of the article, showing the number of citations and linking to the citing content. For the system to work, a journal submits metadata in XML format about each article, including the article's reference list, to CrossRef.org. By deposit article metadata and reference lists in Crossref database makes it possible to display the number of

25 Permalink. Wikipedia. 2020. https://en.wikipedia.org/w/index.php?title=Permalink\&oldid=971336719 (Accessed August $17^{\text {th }}$ 2020).

26 The International DOI Foundation (IDF). The DOI system. 2020. https://www.doi.org/ (Accessed March 21 $1^{\text {st } 2020) . ~}$

27 The International DOI Foundation (IDF). Registration Agencies. 2020. https://www.doi.org/registration agencies.html (Accessed April 11 ${ }^{\text {th }}$ 2020).

28 Crossref.org. 2020. https://www.crossref.org/ (Accessed March $1^{\text {st }}$ 2020). 
citations and lists on articles so readers/researchers can see that the article they are reading is being cited. The OJS support system has these services built in to automatically manage metadata for CrossRef.org. Members can then display the citations and links on their own work and on the article metadata website. ${ }^{29}$

\section{The Construction of a DOI}

Figure 4 below explains how a DOI can be structured. It consists of one prefix (2) and one suffix (3-5).30 The suffix can be structured in many ways. It is, however, important that the DOI is made unique for each article and not too long.

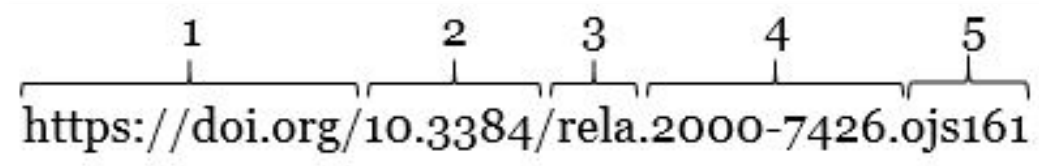

Figure 4. The construction of a DOI.

$1=$ The web link to the resolver, doi.org lookup service which forwards to the landing page (webpage), where the publication is published online.

2 = The prefix 10.3384 belonging to the publisher Linköping University Electronic Press, which publishes the journal.

3 = The suffix with the acronym RELA, which stands for the European Journal for Research on the Education and Learning of Adults.

$4=$ The journals ISSN.

5 = The article number, in this case automatically assigned by the Open Journals System support system.

The article number is the most convenient to use. One can also use a combination of the year of publication, volume, issue and the page number on the first page of the article, for example: 20191327, where 2019 is the publishing year, 13 is the volume, 2 is the issue and 7 is the page number of first page of the article. Such a link would look like this:

https://doi.org/10.3384/rela.2000-7426.20191327

\section{$\mathrm{URN}: \mathrm{NBN}$}

Digital Scientific Archive [Digitala Vetenskapliga Arkivet, DiVA], ${ }^{11}$ is an institutional repository in which Linköping University is a member, and DiVA uses URN: NBN as permanent links for electronic resources. URN is the abbreviation for Uniform Resource Name and is a standard developed by the Internet Engineering Task Force (IETF). $3^{2}$ The National Library of Sweden offers a URN solution for Swedish organizations with a special function of the standard called URN:NBN where NBN is an abbreviation for the National Bibliographic Number. All permanent links in DiVA go through the resolver at National Library of Sweden and are then forwarded to the landing page of respective DiVA member portal.

29 Crossref.org. Cited-by. 2020. https://www.crossref.org/services/cited-by/ (Accessed August 17th 2020).

30 The International DOI Foundation (IDF). Handbook: 2 Numbering. 2020. https://www.doi.org/doi handbook/2 Numbering.html (Access ed April $3^{\text {rd } 2020) .}$

31 Digitala Vetenskapliga Arkivet. About DIVA. 2020. https://info.diva-portal.org/about-diva/ (Accessed March 20 $0^{\text {th }}$ 2020).

32 Internet Engineering Task Force (IETF). 2020. https://www.ietf.org/ (Accessed March 21 ${ }^{\text {st }}$ 2020). 


\section{The Construction of an URN:NBN}

The article Peer review, post printed in DiVA, has the permanent link http://urn.kb.se/resolve?urn=urn:nbn:se:liu:diva-162955 and each link ends with a unique number in combination with the DiVA member's acronym in this case liu.

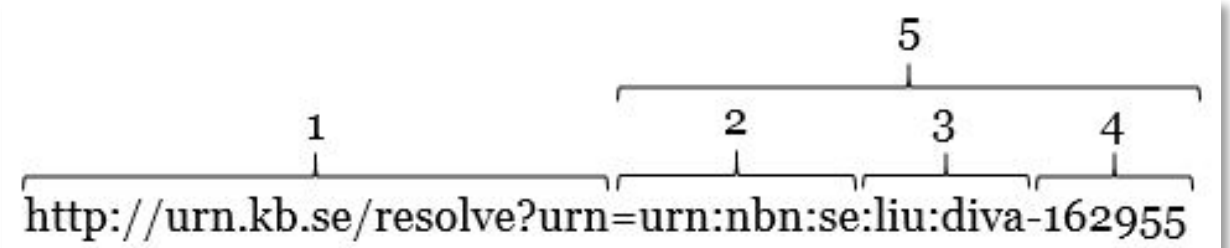

Figure 5. Description of an URN:NBN.

1 = The web link to the resolver is the National Library of Sweden's look-up service which forwards to the landing page (website), where the publication is published online.

$2=$ The namespace that applies to Sweden and is administered by the National Library of Sweden.

3 = Sub-namespace, unique to the organization to which the publication applies.

4 = Serial number or alphanumeric string named by the organization that owns the sub-name space.

$5=$ The unique string that identifies the published resource i.e. publication.

\section{Refer to a Journal Article with a Persistent Link}

Most journals have a suggestion on an article's webpage about how to refer to the article. A reference to a journal article may look different depending which reference system is used. Regardless of the reference system, the persistent link should always be included in the reference. The link should be entered as the last item in a reference. The example below is a reference in the Vancouver reference system. Note that the entire link should be stated:

Gibb, H. Determinants of resilience for people ageing in remote places: a case study in northern Australia, IJAL 2018 Feb; 11(2): 9-34.

https://doi.org/10.3384/ijal.1652-8670.17-333

Note: Never copy the URL from the browser's address bar because these links are often temporary and will stop working after a while. Never link directly to a PDF file but always use the persistent link. Some journals use DOI incorrectly by linking directly to the pdf file, which is not recommended. A correct persistent link always goes to a landing page i.e. a page containing metadata about the article and a link to the pdf file. A pdf file or metadata page can be moved or/and renamed, but the persistent link always goes to the correct landing page.

\section{Broken persistent link}

It unfortunately happens that persistent links do not work. Sometimes it happens when an article is published as Epub Ahead of Print or Ahead of Print or In press, which means that the articles have been published online but are not yet included in any volume, issue or have running page numbers. Some of these articles might have a working DOI, but sometimes it does not work. When clicking on a broken DOI it means the DOI has not yet been deposited at DOI.org. A message will appear with a form as shown in Figure 6 below. It is important to fill in the form and submit the 
information so that DOI.org or CrossRef.org notices that the DOI does not work. They in turn send error lists for action to the publishers and respective journals.

Broken persistent links are often common among predatory journals: non-functional links keep costs down for the predatory journal.33

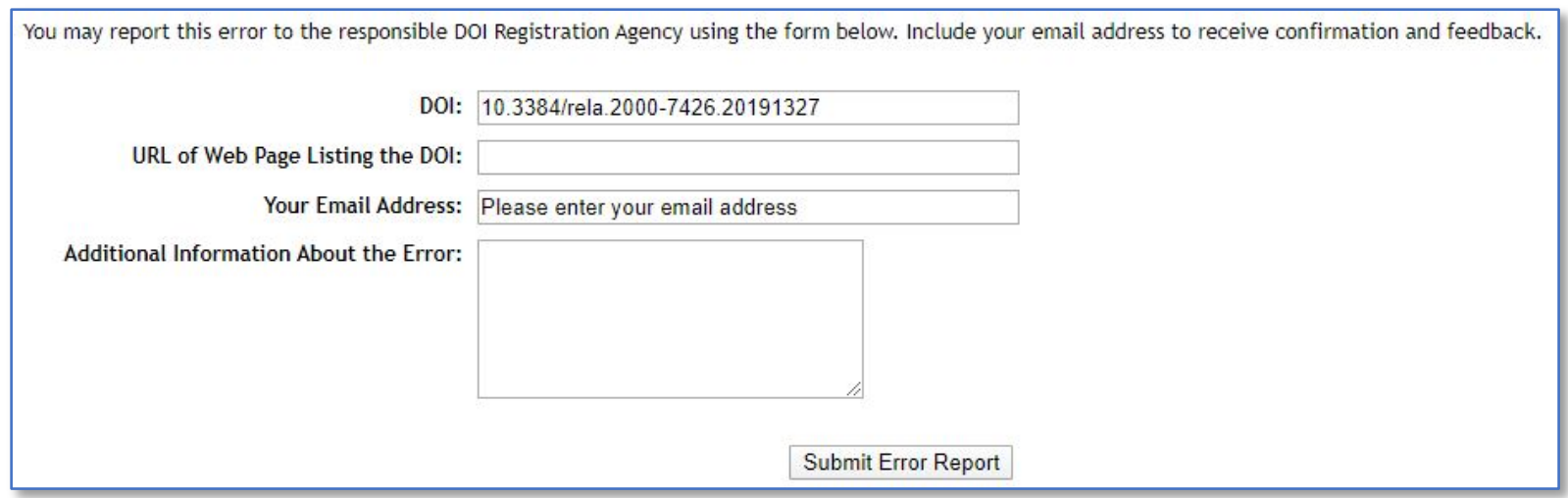

Figure 6. Error message with a form informing that the DOI does not work. The figure is cropped and text above the boxes are removed.

\section{International Standard Serial Number, ISSN}

A periodical journal must have an International Standard Series Number (ISSN). ISSN is an international system for numbering periodicals. The purpose is to identify periodicals of all kinds and develop a reliable register of continuous resources both for printed and electronical publishing. The International ISSN Centre, which administers the ISSN International Centre system, is located in Paris.

The application for ISSN can in Sweden be made via the National Library of Sweden. Resources with an ISSN are catalogued in LIBRIS, 34 the national directory for all Swedish libraries and updated daily.

Notify National Library of Sweden when the first volume and issue of the journal has been published and send a link to the table of contents of the new volume and issue including DOI.

Before applying for an ISSN in Sweden, The National Library of Sweden requires that the journal homepage most be active with at least a volume and issue published in order to get an ISSN.

International Standard Serial Number should not be mixed up with International Standard Book Number (ISBN). Periodicals such as electronic published journals do not need a ISBN even if the journal is published in printed form.

\section{Directory of Open Access Journals}

The Directory of Open Access Journals (DOAJ) 35 is an international independent database containing quality-reviewed, full-text scientific open access journals and covers all research topics and languages. DOAJ was launched at Lund University, Sweden, in 2003 and contained 300 open access journals and today the number of journals has increased to about 12000 open access journals. DOAJ is also co-author

33 Agnes Grudniewicz, David Moher, Kelly D. Cobey et al. Predatory journals: no definition, no defence. Nature, 576. 2019: 210-212. https://doi.org/10.1038/d41586-019-03759-y ; Committee on Publication Ethics (COPE). 2020. https://publicationethics.org/ (Accessed July 21 $1^{\text {st }} 2020$ ).

34 National Library of Sweden. 2020. https://www.kb.se/ (Accessed March 30 $0^{\text {th }}$ 2020).

35 Directory of Open Access Journals (DOAJ). About. 2020. https://doaj.org/about (Accessed January $25^{\text {th }}$ 2020). 
to the Principles of Transparency and Best Practice in Scholarly Publishing and these principles must be followed by DOAJ members as a condition of membership. ${ }^{36}$ The DOAJ website and metadata database are licensed under CC BY-SA.

Journals published as open access should absolutely apply to be included in the DOAJ database. The validation process might take quite a long time and some criteria must be fulfilled in order to be included. At least three issues of the journal should be published before sending in an application to DOAJ. It is important that the journal has clear information on its website about open access, copyright, self-archiving etc. The Public Knowledge Project (PKP) has excellent information on how OJS journals apply to be included in DOAJ. 37 Note that DOAJ mainly relies on information from the journals/publishers themselves but regularly reject titles which does not fulfil the DOAJ quality criteria.

\section{Correct Affiliation}

Proper identification of the author's affiliation in an article is important to ensure that publications are credited to the author and the author's educational institution:

\section{Open Researcher \& Contributor ID}

Open Researcher \& Contributor ID (ORCID) ${ }^{38}$ is an international non-profit organisation and an international register, where researchers can register and obtain a unique researcher ID. The aim is that each researcher should be able to have a unique identifier and thus solve the problem of researchers who have the same or similar names, especially as some journals publish only a researcher's family name and initials instead of the full given name.

\section{The construction of ORCID}

An ORCID consists of 19 characters, of which 16 are digits and three hyphens. Examples of an ORCID:

oooo-0003-2193-1165

It is easy to identify an author who has an ORCID by entering the URL https://orcid.org/ followed by the ORCID itself in a browser's address box. The link will point to the author and author's publications if the publications are imported into ORCID.org.

In a journal, together with the author's name, the complete URL should always be stated with an ORCID icon:

(iD) https://orcid.org/oooo-0oo3-2193-1165 $5^{39}$

In OJS there is a special field for ORCID and the journal should encourage researchers to obtain an ORCID and use it when submitting their manuscript to the journal. Most national and international research funders require that researchers applying for funding must have an ORCID.

36 Directory of Open Access Journals (DOAJ). Principles of Transparency and Best Practice in Scholarly Publishing. 2020. https://doaj.org/bestpractice (Accessed August $7^{\text {th }}$ 2020).

37 Public Knowledge Project (PKP). Appendix 1: DOAJ Application Guide for OJS Journals. 2020. https://docs.pkp.sfu.ca/getting-found-staying-found/en/getting-found-appendix-1-DOAJ (Accessed March 25 $5^{\text {th }}$ 2020).

38 Open Researcher and Contributor ID (ORCID). 2020. https://orcid.org/ (Accessed March $25^{\text {th }}$ 2020).

39 Open Researcher and Contributor ID (ORCID). Journal Article Display Guidelines. 2020. https://orcid.org/content/journal-article-display-guidelines (Accessed April 12 ${ }^{\text {th }}$ 2020). 


\section{Legal Deposit}

Almost all countries in the world have a law about Legal Deposit4o of printed and/or electronic publications. According to the Swedish law about Legal Deposit, 41 a publication or document is liable for delivery for Legal Deposit if it is multiplied (i.e. printed), published and intended to be made available to the public or a wider closed circuit. In order for a publication to be considered to be published and distributed, it must be manifold, i.e. printed, copied or otherwise produced in a larger number of copies.

In general, the printing companies (in Sweden) arrange for legal deposit copies to be sent to recipients. If the journal is going to be printed as well check with the printing company that they also send legal deposit copies to the national library or the country. One tip is to also send a copy to your own university archive.

\section{Electronic Legal Deposit}

In Sweden on July 1, 2012, the law of Legal Deposit of Electronic Material came into force. The law applies to electronic material made available from 1 January 2015. This also includes all journals published via the Internet which must send a digital copy to the National Library of Sweden. ${ }^{2}$

40 Legal Deposit. Wikipedia. 2020.

https://en.wikipedia.org/w/index.php?title=Legal deposit\&oldid=953072160 (Accessed April 29 $9^{\text {th }} 2020$ ).

41 Pliktexemplar [Legal deposit]. Wikipedia. 2020. https://sv.wikipedia.org/w/index.php?title=Pliktexemplar\&oldid=46151811 (accessed 2020-0302); National Library of Sweden. Legal Deposit. 2020. https://www.kb.se/in-english/aboutus/how-we-collect-material/legal-deposit.html (Accessed March $2^{\text {nd }}$ 2020); Legal Deposit. Wikipedia. 2020. https://en.wikipedia.org/w/index.php?title=Legal deposit\&oldid=947988817 (Accessed March $2^{\text {nd }}$ 2020).

42 National Library of Sweden. E-Legal Deposit. 2020. https://www.kb.se/in-english/aboutus/how-we-collect-material/legal-deposit/e-legal-deposit.html (Accessed April 29 $9^{\text {th } 2020)}$. 


\section{Organise the Journal and the Administration}

\section{Publishing Strategy}

As mentioned before, the work of publishing a journal requires some time and effort. A commercial publisher, the host, normally takes care of the work on the formatting and finalization of articles, but for a journal, without a publishing host, that is to handle everything themselves, all this work must be done by the responsible editor and the editorial team. Linköping University Electronic Press (LiU E-Press), for example, only hosts journals and each journal handle the editorial work themselves. LiU E-Press does, however, check each article that the DOI, page numbering i.e. the metadata contents are correct and correspond to the article contents.

\section{Publishing Frequency and Method}

It is important to determine a publishing cycle for each volume and issue i.e. how many volumes to publish per year and how many issues per volume. Based on the publishing cycle it is easier to organise and plan how much work it will be for each volume and issue.

Should articles be published with continuous publishing, as they are accepted, proofread and formatted, or collected into a volume and issue? If articles are to be published continuously and not included in volume or issue, each article should be assigned a number, an article number, to make it easy to create a reference to the article. Page numbering need not be continuous but can be individual for each article i.e. articles' page numbers always start with page 1 . Of course, one can choose both options: articles are published continuously in a certain order with ongoing page numbering and when the editors consider that sufficient articles are enough then all articles are published as a volume and issue. Articles can also be pre-published (advance access) and then be included in a volume and issue where the articles are provided with a volume and issue number and running page numbers. This type of publishing is becoming more and more common and used by several commercial academic journals.

The number of volume and issues per year is important to determine in advance and then relate to the publishing intervals. Continuity in publishing the journal's volumes and issues each year is important so that a journal is perceived as serious. Each issue should contain at least four to five articles, preferable more, introduction and book reviews not included.

\section{Economic Plan}

An economic plan is an essential prerequisite for a journal's survival. The plan should include a fairly detailed overview of the costs that the journal has to deal with: How many volumes and issues are planned to be published per year.

- Staff and administrative costs

- Conference trips to market the journal.

- Marketing in general.

- Editorial meetings and editorial work.

- Editing.

- Proofreading.

- Graphic design.

- Software.

- Technical equipment and technical support. 


\section{Economic and Scientific Support}

Depending of which open access model is selected, publishing can be financed either by author fees or grants from leading national or international research funders. But the journal can be commercially financed provided the publisher or the University allow you to finance the journal by using a commercial approach. A source of revenue for the journal can also be by advertising, sponsorships and print-on-demand. 43 No matter what kind of commercial financing the journal chooses it is very important that the funding does not influence the editorial work and the journal content including published articles. There should under no circumstances be room for any slight suspicion of influences from the advertisers. It is the editors who have the responsibility of the contents of the journal including the sponsorship and advertising. It is therefore very important that a journal has a very clear policy of what kind of sponsoring and advertisement the journal allows and that the contract between the parties is very clear and detailed regarding the above policy. 44

But it is also very important and necessary to have scientific support as well. Scientific support is crucial for a journal in order to market the journal and to make the journal attractive for prospective writers who may be submitting manuscripts to the journal and by that create the journal's trademark.

\section{Economic Support}

The costs of the journal, which arise from the publication of the journal, can be alleviated by seeking grants from research funds. In Sweden The Swedish Research Council 45 provides grants for open access journals of the highest scientific quality and the Swedish Research Council for Health, Working Life and Welfare ${ }^{46}$ provides funding for the publication of Swedish and Nordic journals, but also for Englishlanguage journals. The Nordic Board for Periodicals in the Humanities and Social Sciences (NOP-HS) 47, which supports Nordic journals "of the highest quality that promote renewal in the research field". Three requirements must fulfils: must have a Nordic foundation, have an external peer review system and indexed in international databases on a regularly basis. See the respective websites for more information and contact. Check which other research funders provide financial support for open access journals.

\section{Support from the Department at the University}

If a journal's publishing host is a University in general, a University Library or a department at an educational institution, there should be support from management for the operation of the journal. Support can be scientific, administrative, financial or all. Note that support does not necessarily mean money but can also be done through the provision of staff resources.

43 Iverson, Cheryl. AMA manual of style : a guide for authors and editors, $10^{\text {th }} \mathrm{ed}$. American Medical Association, 2020. ISBN: 9780190246556.

44 SPARC. Sponsorships for Nonprofit Scholarly \& Scientific Journals: A Guide to Defining \& Negotiating Successful Sponsorships. Release 1.0, July 2005. 2020. http://www.sparc.arl.org/sites/default/files/Sponsorship Guide.pdf (Accessed July $1^{\text {st }}$ 2020). Swedish Research Council. 2020. https://www.vr.se/ (Accessed January 17 th 2020).

46 Swedish Research Council for Health, Working Life and Welfare (FORTE). 2020. https://forte.se/ (Accessed January $17^{\text {th }}$ 2020).

47 Journal Grants. The Nordic Board for Periodicals in the Humanities and Social Sciences, https://www.aka.fi/en/nos-hs/calls/journal-grants/ (Accessed March 17th 2021). See also Swedish Research Council, https://www.vr.se/soka-finansiering/utlysningar/2018-o6-21-nop-hsscientific-journal-grant.html (Accessed March 17th 2021). 


\section{International Support}

Supporting a journal does not always mean economic but scientific. International scientific support by researchers within a journal's scientific area is crucial for the existence of a journal. Support, can of course, also be financial, administrative or editorial. If a journal is an international collaboration within a specific research area, support will automatically be international.

\section{Sponsors}

A journal can be sponsored by operators who can be either commercial, academic or by other stakeholders interested in scholarly publishing within the research area. The alternative to commercial operators can be purely academic, such as sponsoring by one or more universities, research institutes or private financiers who act within a specific research area that the journal covers. Sponsorship might be a pre-determined annual sum for one or several years between one or more sponsors and the journal, according to a contract. In return the journal publish the sponsor's logo either in the journal for each volume and issue or on the journal website.

\section{Advertising}

Another way of funding a journal, and perhaps more controversial than sponsorship, may be revenues through advertising on the journal's website. This type of financing a journal is very unusual. It does not necessarily have to be products only, but also services, connected to the journal's research area, that are displayed in advertising. This advertising must go through a detailed control and be respectable in the sense that the advertising must not take over or have any influence over the content of the journal. There is a risk that the journal can be regarded as a predatory journal. It is also not certain that the publisher, who is hosting the journal, allows advertising on their server and web pages. If the journal is published under its own publisher i.e. an academic institution, the process will of course be simpler and the journal itself decides on the presence of advertising on the web pages but still must get permission from the institution. However, usually Universities have strict policies and rules regarding advertising on their webpages.

\section{Publishing Certificates}

In Sweden, all Swedish citizens have the right to publish periodic publications freely in accordance with the Freedom of the Press Act [Tryckfrihetsförordningen]. ${ }^{48}$ In accordance with the Freedom of the Press Regulation, the publisher must have a certificate of publication in order to publish a journal in print form and that it is published at least four times a year with the same journal name. The applicant for the certificate is also the person responsible for the publishing. The certificate of issue is assigned by the Swedish Intellectual Property Office [Patent- och Registreringsverket (PRV)] $]^{49}$ and is valid for ten years and must then be renewed. If the responsible publisher is replaced, this must be reported to the PRV. If the journal is only to be published electronically via the Internet, no certification is needed, but on the other hand it may be wise to protect the journal's trademark which can also be made via PRV.

48 Freedom of the Press Act [Tryckfrihetsförordningen] (1949:105) to SFS 2018:1801; Nordin, Jonas. 1766 års tryckfrihetsförordning: Bakgrund och betydelse. 2015, Stockholm: Kungliga biblioteket.

49 Swedish Intellectual Property Office [Patent- och Registreringsverket PRV]. 2020.

https://www.prv.se/en/ (Accessed January 17 $7^{\text {th }}$ 2020). 
It is also possible to apply for a certificate of publication from the Swedish Press and Broadcasting Authority [Myndigheten för press radio och tv (MPRT)]. $.5^{\circ}$ A certificate from MPRT for Internet publishing, the publication is protected by the Fundamental Law on Freedom of Expression [Yttrandefrihetsgrundlag] in the same way as for radio, television and newspapers. This means that the General Data Protection Regulation (GDPR) ${ }^{1}$ no longer applies and does not affect the publication of personal data such as name and address and you do not need permission from the people in question. However, if the journal is only published electronically, this certificate is not recommended. It will also save the editorial team some extra work not applying for the certificate.

\section{Prices}

Swedish Intellectual Property Office and the Swedish Press and Broadcasting Authority charge a fee for the application for publication certificate, for a change of title or change of publisher or owner. There is also a cost for the renewal of the certificate every tenth year. See the respective government authority's website for more information on prices.

\section{Editorial Office or Editorial Team}

A journal's management and administration consist of an editorial office located at the publisher or at a University depending where the journal is hosted. The latter can be geographically dispersed depending on how the journal's work is organised. It is common for a journal to collaborate with researchers at several different Universities, which means that the staff of the editorial office may be scattered at several Universities or Colleges. Regardless of the organizational structure, it is of course important that administration and communication work smoothly and are costeffective.

Each accepted manuscript must undergo editorial formatting work so that all manuscripts to be published always have a uniform graphic design. This means that fonts, headings, quotes, references, reference lists, tables and charts etc. are designed so it always looks the same in every release. For this to work, a number of people are involved who are part of the staff of the editorial office, which consists of several different positions:

- editor in chief

- assistant or associate editor

- review editor

- editorial board

The above list shows the most common titles within a journal administration but there can be a wide variety of editors such as design editor, copyeditor, proof-reader, manuscript editor, guest editor, web editor etc. A member of the editorial staff can have two or more editor roles.

\section{Editor in Chief}

A journal must have a responsible Editor-in-Chief. It can either be one or more people who share the responsibility but usually it is only one person. The Editor-in-

50 Swedish press and broadcasting authority [Myndigheten för press, radio och tv]. 2020. http://www.mprt.se/en/ (Accessed January 17th 2020).

51 The Swedish Data Protection Authority [Datainspektionen]. General Data Protection Regulation (GDPR). 2020. https://www.datainspektionen.se/other-lang/ (Accessed January 17 $7^{\text {th }}$ 2020). 
Chief holds the position for a number of years and is then replaced by a new Editorin-Chief. The editor-in-chief should be a senior researcher and preferably internationally known in the research area and, rather, at the professor level with good international contact networks. The editor's duties include among other things:

- Head of the editorial team and journal administration.

- Responsible for the journal's finances.

- Responsible for the academic quality of the journal.

- Responsible for the appointment of the editorial board.

- Chair at meetings and other internal work for the journal such as administration, finance, budget, staff, etc.

- Responsible for the marketing of the journal.

- Validate incoming manuscripts and decide whether to proceed with review or rejection.

- Ensure that a manuscript is undergoing a quality peer-review process.

- Determine whether the content of a manuscript is scientifically objective.

- Approve that the accepted manuscript may be published.

- Handle incoming comments, complaints etc. from readers.

\section{Assistant or Associate Editor}

Depending on the journal's publishing frequency and thus the workload, the journal's Editor in Chief may delegate work to one or more Assistant or Associate Editors. The role of Assistant Editor may vary between journals, but the purpose is to relieve Editor in Chief by taking over some of the work.

\section{Review Editor}

Most journals also publish book reviews either in all volumes and issues or in selected ones. This work is handled by the Review Editor who can choose which books to review or take suggestions from other researchers within the research area. The Review Editor then ensures that the assignment to review is performed and that the review holds a scientifically high quality.

\section{Editorial Board}

The editorial board, is absolutely crucial to a journal's survival. The board is a composition of several subject experts within the research area who can advise on the journal's publishing strategy. The editorial board responsibility and work includes:

- Advise and support the editor in chief.

- Be a guarantor of the journal's credibility.

- Act as an ambassador for the journal in order to associate other researchers with the journal or other important experts in the research field.

- Ensure that journal articles are published according to the journal aim and scope.

- Acts as a support for attracting prospective writers to the journal.

- Identify and propose appropriate conferences for the journal editors to attend.

- May promote the journal at conferences, seminars or at other official or informal gatherings.

Members of the editorial board should be international, composed of leading researchers in the journal's research area and it is especially important that all continents are represented with as equal gender distribution as possible among the editorial members. The editorial members' affiliation must also be included such as 
the University/College name, country and e-mail address. The name Editorial Board may vary among journals such as Editorial Team, Editorial Committee, Consulting Editors, Editorial Advisory Board or Advisory Board.

\section{Journal Name}

First make sure the journal name is not taken by anther publisher/journal. The name of the journal is very important and should reflect the research area/subject and should be a Descriptive title i.e. a description of the journal research area/research subject. The journal name should not be possible to be mixed up with an existing journal. If the journal is international the word International must definitely be included in the journal name to declare it is a worldwide journal. If the journal only turns to scholarly research of a part of the world the name should contain a suitable name such as Scandinavian Journal of..., African Journal of... or Asian Journal of etc. or even a country name can be part of the journal name such as The Swedish Journal of Economics. The journal title should not be too long or complicated and easy to turn into an acronym.

It is important that the journal's brand is not the same as that of the publisher. The journal's brand should be able to "stand on its own", which is especially important if the journal chooses to change publishers.

\section{The Journal Language}

In order to reach as widely spread audience as possible for a journal English is recommended as the journal's language. English is the most used language in scientific communication and publishing around the world. It is, of course, the journal editors who finally decide what language to use before launching a journal. If a journal is aimed at a smaller public for example Scandinavia the journal's language can, beside English, also include Danish, Norwegian and Swedish. Even if the article is written in a Scandinavian language, it is still desirable that the abstract is written in English. This enables a wider audience, to take part of the content without reading the article.

If English is the journal's language it is also necessary to decide which version of the English language to be used. There are a lot of versions of English to select among such as American, Australian, Canadian, India or South African English to mention some of them. One sometimes can see a mix of both British and American English in a published article which is not to recommend because the vocabulary, spelling and grammar varies between the different versions. This paper, for example, is written in British English.

\section{Scientific Review}

\section{Peer Review}

Peer review $5^{2}$ means a review (analysis, check) of the manuscript by researchers in the same research field or research subject under which the journal is published.

52 Peer Review. Wikipedia. 2020.

https://en.wikipedia.org/w/index.php?title $=$ Peer review\&oldid $=954565841$ (Accessed May $5^{\text {th }}$ 2020); Kanu Okike, Kevin T. Hug, Mininder S. Kocher \& Seth S. Leopold, Single-blind vs Doubleblind Peer Review in the Setting of Author Prestige, JAMA, 316(12), 2016: 1315-1316, https://doi.org/10.1001/jama.2016.11014; Samir Haffar, Fateh Bazerbachi \& M. Hassan Murad, Peer Review Bias: A Critical Review. Mayo Clinic Proceedings, 94(4), 2019: 670--676. https://doi.org/10.1016/j.mayocp.2018.09.004. 
There are usually two systems used for peer review: single-blind review or doubleblind review. Single blind review, the reviewers know the identity of the author but the author do not know the identities of the reviewers. Double blind review, means that the author and the reviewers do not know the identity of each other. Most journal use double blind review but there are exceptions. Note that there are journals that apply triple blind and / or quadruple blind reviews, the latter more uncommon.

The peer review system has been exposed to criticisms being not a trustable system for scientific validating of scientific manuscripts. Despite the criticism, peer review is important and still the only widely accepted method for validating and maintaining hight quality research published in a scholarly journal. Peer review is also of benefit for the author: the review can notify the author to any errors in the manuscript such as text, inconsistence, figures, tables etc. or missing references that might have been overlooked and, most important, the review process often improves the quality of the submitted manuscript. 53

Therefore, a submitted manuscript to a journal must undergo a scientific review process to uphold high quality standard of each published article in the journal and double-blind peer review is highly recommended.

Note: When an author writes an article for example, in Word, there is a great risk that the author's name is included in the properties of the Word file. This information must be removed before the manuscript is sent to reviewers.

An average workflow of a submitted manuscript is shown in figure 7 including the reviewing process. This workflow can, of course vary between journals but the example is a simple description how the manuscript is handled after being submitted to the journal. Note that some journals have different routines handling the plagiarism check: run the plagiarism check after receiving the manuscript goes before sending the manuscript to reviewers or run the plagiarism check after the review process. A plagiarism check is very important not only to see if the manuscript contains any kind of plagiarism but also avoid copyright infringement.

\section{Open Review}

An option to single or double-blind reviewing is open review.54 Open peer review means that the authors know who the reviewers are, and the reviewers know who the authors are. If the manuscript is accepted and published, the reviewer's names and review reports are published along with the article. This system is very transparent for viewers but labour intensive for the editors due to the extra work of publishing each review process, any changes in the manuscript during the review process and create a new version of the html page and pdf file. A list of the previous versions must be published with possible to access and read earlier versions of the article.

53 Ann T. Gregory \& A. Robert Denniss. Everything You Need to Know About Peer Review - The Good, The Bad and The Ugly. Heart, Lung and Circulation, 28(8), 2019: 1148-1153 https://doi.org/10.1016/j.hlc.2019.05.171; Jelte M. Wicherts, Peer Review Quality and Transparency of the Peer-Review Process in Open Access and Subscription Journals, PLoS ONE (1), 2016: e0147913. https://doi.org/10.1371/journal.pone.0147913; Steven W. Sowards, What is Peer Review, and Does it Have a Future? Bibliothek Forschung und Praxis, 39(2) (2015), https://doi.org/10.1515/bfp-2015-0024; Fytton Rowland, The peer-review process, Learned Publishing 15(4), 2002: 247-258. https://doi.org/10.1087/095315102760319206.

54 Tony Ross-Hellauer, What is open peer review? A systematic review, PMC T. 2017: 6:588, F100oRes. https://doi.org/10.12688/f10ooresearch.11369.2; Open Peer Review. Wikipedia. 2020. https://en.wikipedia.org/w/index.php?title=Open peer review\&oldid $=953120745$ (Accessed May 14 ${ }^{\text {th }}$ 2020). 
Figure 7, below, illustrates a simple flow chart of the review process. The review flow various, of course, between journals depending on which review system and level the journal has chosen.

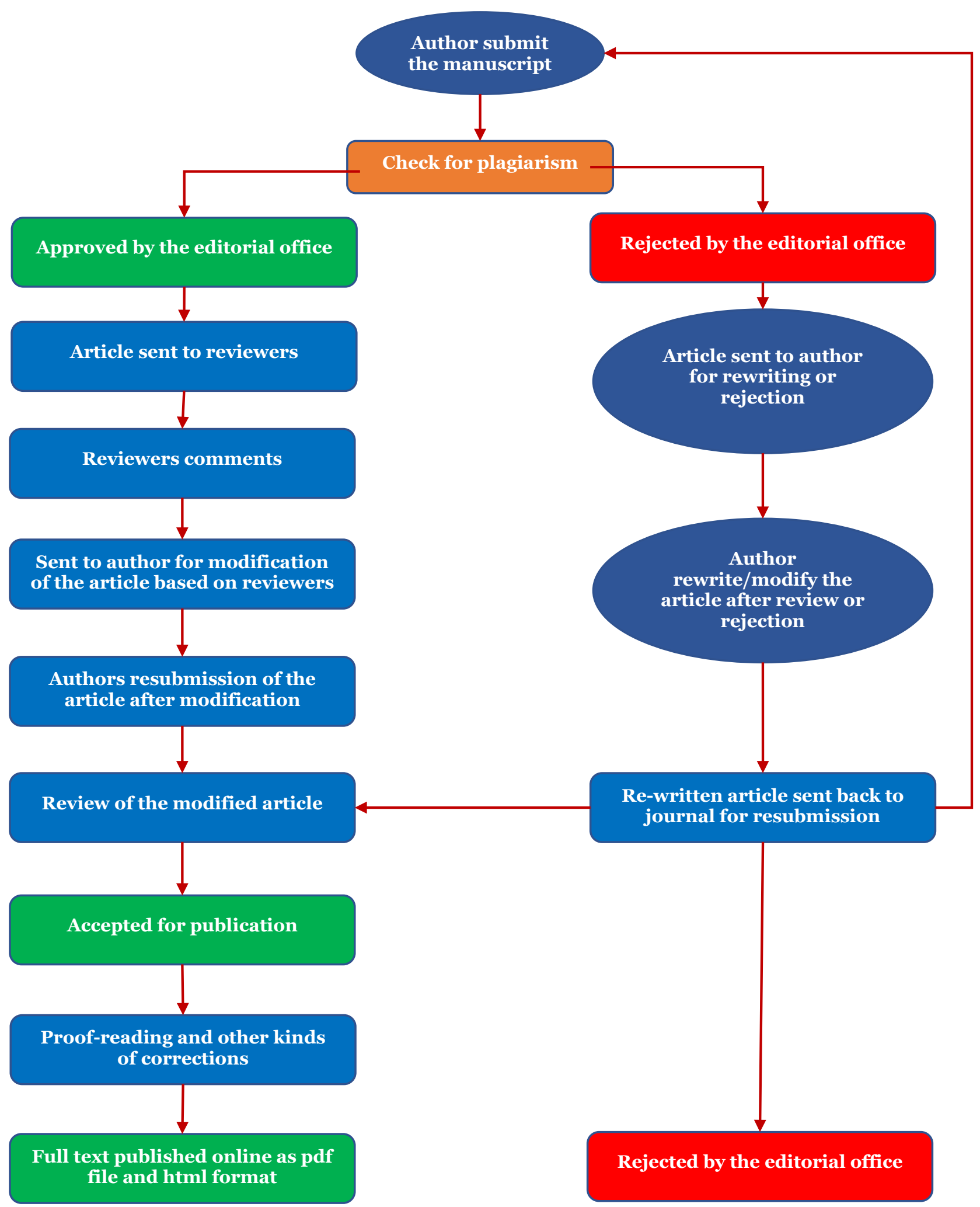

Figure 7. Example of a minimum workflow steps of submitted manuscript. 


\section{Copyediting and Proof-reading}

The submitted manuscript must undergo copyediting and proof-reading to check for grammar and spelling errors, punctuation, capitalization, font usage, numerals, hyphenation, highlights like bold and italics, spacing, underscore etc. It is very important that all accepted articles have correct English, consistency, names etc. in all forms before publishing. That raises the reputation of the journal. The work a copyeditor and proof-reader do is very similar but there are some differences between them. Similar to both is that they both do a "page makeup" of the manuscript to avoid any error what so ever.

\section{Copyediting}

A copyeditor reads the manuscript and:

- Corrects errors in grammar, spelling, syntax and punctuation.

- Check for technical consistency in spelling, capitalization, font usage, numerals, hyphenation. For example, is it "post-print" on one page or "pre-print" on another page? Or is both British and American English used in the manuscript with the spelling variations such as "colour" or "color" or "through" or "thru"?

- Review for factually incorrect statements or names in the manuscript are correct.

- Check that person names, product names etc. are correct and consistence throughout the text.

- Check for possible legal liability and verifies that the manuscript does not accuse or offend anyone.

A copyeditor may also, if necessary, suggest minor or major changes and can rewrite text, to correct any problems with transitions, wordiness, abbreviations etc. and i.e. make revision.

\section{Proofreading}

If the journal's language is not the native language for an author it is recommended using a proof-reader to ensure there are absolutely no errors in the manuscript before publishing. A proof-reader will look for spelling errors, punctuation errors, typos or incorrect use of regional English. A proof-reader does similar work to the copyeditor but does not suggest minor or major changes in the manuscript i.e. no re-writing or revision. A proof-reader does a final check to ensure there are no text or formatting errors in the text and make sure there are absolutely no errors in the manuscript.

\section{Publish Research Data}

The definition of research data often differs depending on the research area in question. Generally, research data refers to the results of processed data of various kinds, observations or experiments that validate the research results. These include a number of useful materials associated with the research project:

- raw data or/and processed data files

- spreadsheets

- software

- questionnaires

- transcripts

- codebooks

- laboratory reports 
- audiotapes, videotapes

- photographs, films

- test responses

- chemical formulas

- codes that is not software

- research models

- algorithms or other mathematical formulas

- protocols

- research methods

Research data does not include text in manuscripts or the final published article, data or other material submitted and published as part of the journal article. 55

\section{Why Publish Research Data?}

In addition to the fact that research financers may require publication of research data in order to receive funding, there are several reasons why a researcher should, or at least consider publishing their research data. By sharing research data, it can help the scientific community by allowing reproduction of e.g. an experiment. If the researcher publishes the research data, other researchers can, in detail, examine the research data, research methods and analysis methods, which can give rise to new scientific studies and research results. It can also lead to new collaborations between researchers at different universities and research institutes. If research data is public, it may lead to higher visibility on the Internet and thus increased citations of the article. Publishing research data could be a great way to archive their data for future use. Finally, publishing research data is an excellent way to show that the research is transparent and performed in good academic practice.

Research data can be published either together with the article or as a separate entry with its own DOI and links between the article metadata page and research data metadata page. If the research data is published by itself i.e. as a separate post (record) with a DOI it is possible to cite the post with research data just like for the article. 56

Note that research data that is part of a patent application or is to be reused and supplemented in other unpublished articles within the research project should definitely not be published until the patent is ready or before the research project is completed. Research data that is published must not contain sensitive personal data so that it is possible to identify the persons included in a study.

OpenAire recommend not using Creative Commons license CC BY for research data. They recommend instead, that the owner of the research data ask for credit i.e. a reference to the published research data. 57

\section{Publishing Agreement and Terms}

It is an essential responsibility of a journal that there are written and signed publishing agreements between the journal and the authors before an article can be published. Every author who publishes their article in a journal must sign a

55 Elsevier. Sharing Research Data. 2020. https://www.elsevier.com/authors/authorresources/research-data (Accessed July 26th 2020).

56 The link in this note goes to an example where research data has been published in the institutional repository (DiVA) for Linköping University with a link to the original article: http://urn.kb.se/resolve?urn=urn:nbn:se:liu:diva-148013 (Accessed July 26 ${ }^{\text {th }}$ 2020).

57 OpenAire, https://www.openaire.eu/research-data-how-to-license/ (Accessed March $18^{\text {th }}$ 2021). 
publishing agreement and this agreement should then be archived. The publishing agreement regulates the journal's obligations towards the author and the author's rights such as reusing the contents of the article, self-archiving etc. If there are more than one author of an article, either all authors can sign or they can agree that the corresponding author $5^{8}$ signs the agreement on behalf of all authors. Regardless of whether one chooses to publish under Creative Commons or not, there must be a signed agreement between the journal and the author in order to be legally valid in the event of a legal conflict.

There should also be a signed publishing terms between the journal host and the journal. The purpose is to document the publisher's and the journal's obligations towards each other, the publishers publishing policy and conditions. It is necessary with a legal document if a legal problem arises between the parties.

\section{Journal Reference System}

References in a scholarly article is very important. There are several purposes of having references:

- To confirm and validate the article research data.

- By citing the work of a scholarly researcher, you give acknowledgement to the researchers work.

- Recognise the intellectual property rights of the researcher you have cited.

- The references do also support the assertions and research results in your work.

- It makes it possible for the readers to trace the sources and examine the sources of your work.

- By the citation, point out what material is your own original work and what material that is not your own.

- Avoid accusations of plagiarism by clearly showing the research sources and maintain academic integrity. 59

There are several different references system that can be used and these systems is divided into three main categories:

1. documentary notes styles

2. parenthetical (also known as author-date) styles

3. numbered styles

Within these three categories there are several other different reference styles depending of what reference system the journal decides to use:

1. Documentary note styles. The Documentary note styles references uses a symbol or a number (digits) in the text in order to refer to a reference in footnotes or endnotes. are given in footnotes or endnotes. The reference can be stated at the bottom of the page as a footnote or as an endnote in the end of the article or chapter. The most known documentary note style is Oxford reference

58 If an article has more than one author it is the corresponding author the author who has the responsibility with the communication between the authors and the journal where the article will be published in.

59 UNSW Sydney, Why is Referencing Important?, UNSW Sydney. 2021, https://student.unsw.edu.au/why-referencing-important; References. Wikipedia, 2021. https://en.wikipedia.org/w/index.php?title=Reference\&oldid=999564519 (Accessed March 24th 2021). 
system but there can also be special systems within a certain research area that uses digits in brackets in the text and the reference list. 60

2. Parenthetical styles or author-date styles. In parenthetical references the reference is given within parentheses and embedded in the text, within or after the sentence. Most used parentheses reference system is American Psychological Association (APA), Harvard and Modern Language Association of America (MLA). ${ }^{61}$

3. Numbered styles (also known as author number system) refer to the source with Arabic numbers), placed within square brackets or in superscript (superscript is the number or letter, shown slightly above the normal text as the notes in this publication). The references are then listed in a numbered reference list after the article text and numbered in the order as they appear in the text. The most known numbered systems are Vancouver and Institute of Electrical and Electronics Engineers (IEEE).

An elemental rule when referring to sources used in your work, is that references must be accurate, complete and should be consistently applied throughout the article. ${ }^{62}$

Different academic disciplines use different reference systems, mainly because a particular reference system work better with the text that are most commonly used within a certain research discipline. Depending of the journal research discipline the journal must decide which reference system to use in order to maintain consistency in all articles.

If the journal determines to limit the use of characters in the article i.e. the article must not overrun a certain numbers of characters, including spaces between words, punctuation, numbers and references in the text, the editorial board has to decide whether the references in the text should be included in this limitation or not.

The reference list is important because it must be uploaded to CrossRef.org after given the article a DOI in order to make the citation system (cross references) to work (see the headline Persistent Links). If available, always include the persistent DOI after a reference in the reference list.

\section{Manuscript Template}

In order to save work and time for the editors, a manuscript template is a shortcut. The template can be downloaded under the instructions for authors on the journal's website. A manuscript template defines how the manuscript document should look like when it is submitted to the journal. It includes which font to use, font size, where the main heading, authors' names and affiliation, abstract and keywords are to be placed, how subheadings, paragraphs, quotes, references, reference list, figures and figure text, tables and table text etc. should look like when the edited article is finally published online and / or printed. Of course, it is not possible to get a fully finished article from the author but some additional work is almost always required and the

60 Lund University. Different kinds of reference styles, Lund University, https://awelu.srv.lu.se/sources-and-referencing/using-a-reference-style/different-kinds-ofreference-styles/ (Accessed March 25 ${ }^{\text {th }}$ 2021).

61 Parenthetical referencing. Wikipedia. 2021. https://en.wikipedia.org/w/index.php?title=Parenthetical $\_$referencing\&oldid $=1012948136$ (Accessed March $25^{\text {th }}$ 2021).

62 Izet Masic, The Importance of Proper Citation of References in Biomedical Articles, Acta Informatica Medica, 21(3), 2013, p. 148. https://doi.org/10.5455/aim.2013.21.148-155 (Accessed March 26th 2021). 
habit of handling for example Word can vary among authors. The template should therefore contain instructional text for the author so that he or she knows how to use the template.

The template should contain information what reference system to use and instructions how to write the references. Some journal might have their own references system instead of using the most common systems. The primary thing is that the reference system works with the scientific text.

If the journal handles advanced mathematical characters, formulas, equations, etc. Word may not be very suitable. Instead, $\mathrm{LaTeX}^{63}$ is recommended for more advanced mathematical formulas and a LaTeX template should be available on the journal website.

The journal may require that the template should always be used and if a manuscript is submitted and is not written with the help of the template, the journal might reject the manuscript.

\section{Plagiarism Check}

In scientific publishing, submitted manuscripts may contain plagiarism of other authors' scientific ideas, texts, figures, models etc. With the access to the Internet, it can be tempting to take a shortcut and plagiarise and any plagiarism does not have to be large textual masses but can be figures of various kind, photos, tables or a piece of text that is not considered as a quote. It is important to know that plagiarism is also copyright infringement. It is therefore important that a journal, as standard procedure, performs a plagiarism control of submitted manuscripts before the process of graphic design and formatting of the article begins. Plagiarism is not necessarily done on purpose but can be accidental by forgetting a reference, quotes or rephrasing a paragraph. Note that it is the editor or the journal who decide if a plagiarism check should be done.

Small part of the text in an article might look like plagiarism but sometimes it can be difficult to avoid miner plagiarism. This can happen if several researchers are involved in a major research project that generates a number of scientific articles. In this case, for example, the research method part of articles is often the same because authors are researching within the same project. In these cases, it may be difficult to avoid "plagiarism" and when it happens it may be a good idea to inform the reader of the circumstances.

Another type of plagiarism is self-plagiarism. This means the author reuse previously published research into a new article. It can be minor or major parts of text or figures, tables etc. This is an ethical dilemma that the journal has to deal with. If a figure is taken from a previous published article it must be clearly stated in the new article that the figure is republished and a full reference to the original source. Regarding text from previous work, it can be published as quotation in the new article with full reference to the source.

CrossRef.org offers its members an excellent service called Similarity Check ${ }^{64}$ with the very powerful algorithm iThenticate ${ }^{65}$. The advantage of using the service via

63 The LaTeX Project. LaTeX - A document preparation system. 2020. https://www.latexproject.org/ (Accessed March 18 $8^{\text {th }}$ 2020).

64 CrossRef.org. Similarity Check. 2020. https://www.crossref.org/services/similarity-check/ (Accessed March 22nd 2020).

65 iThenticate. Publish with Confidence. 2020. http://www.ithenticate.com/ (Accessed Mach 22 ${ }^{\text {nd }}$ 2020). 
CrossRef.org is that almost all serious commercial publishers of scholarly journals make use of the service. ${ }^{66}$ The tool works through billions of scientific documents and websites and compare it to the manuscript.

When using Similarity Check it is important to know that it requires a very careful analysis of the checked article in order to be sure if marked text really is plagiarism or not.

Note that if the publisher of the journal, is a member of Crossref, iThenticate gives a discount on its service by the publisher contributing material to its database when registering articles with DOI.

\section{Print on Demand}

Although a journal is only published in electronic form, there are, libraries, institutions and others, who would like to have a printed copy of one or more editions. To meet this requirement, the journal can offer print on demand, 67 a service to order a printed copy at cost price and have it delivered by ordinary mail. Such a service can be more costly for the journal because it requires a bit more work with setting up the journal's website. For example, an order and payment page are needed for payment via invoice or credit card. In order for this to work, collaboration with a printing company is necessary that receives the order, prints and delivers the order. Via print on demand it might also be a revenue source for the journal.

66 CrossRef.org. Similarity Check Fees. 2020 https://www.crossref.org/fees/\#similarity-check-fees (Accessed March 22 ${ }^{\text {nd }}$ 2020).

67 Print on Demand. Wikipedia. 2020. https://en.wikipedia.org/w/index.php?title $=$ Print on demand\&oldid=941742271 (Accessed April $11^{\text {th }}$ 2020). 


\section{The Journal Website}

\section{Accessibility of the Websites and Mobile Applications}

In December $2^{\text {nd }} 2016$ published the EU directive ${ }^{68}$ which aims to give all EU countries laws aimed at increasing digital accessibility for all users, including people with disabilities such as reading difficulties or visually impaired. This means that a website or apps must be adapted so all visitors, regardless of disability, have the same conditions to absorb the information. The directive means that the whole of Europe has the same minimum requirements regarding digital accessibility. However, EU Member States are free to set a higher minimum level. The directive is mainly for the public sector such as government authorities, Universities, city councils, public institutions etc. If the research journal is published within a public sector, the journal must follow the EU directive.

\section{Design and Publish the Journal's Website}

A journal's website should be published online at least a year before the first volume and issue is ready for publishing. The website is a very important source of information for prospective authors. It is here the journal can refer to and inform potential authors as they would like to have more information about the new journal and, most important, read the Aims and Scope of the journal and Call for papers. It is on a journal's website that articles are published electronically. The journal website must be up and running before applying for ISSN or membership at CrossRef.org.

The website should contain information about:

- The aim and scope of the journal

- The names of the members of the editorial board and staff which include affiliation, country and e-mail address

- The number of volumes and issues published per year

- Guidelines for authors i.e. general instructions about organizing manuscripts before submission to the journal

- Instructions about what reference system to use, how to make a reference, guidelines for figures, tables, photographs etc.

- Publishing template for the manuscript

- Copyright information

- $\quad$ Peer review system (i.e. single or double blind)

- The journal's rules about post-prints on institutional repositories as well on authors' personal websites

- Information if the journal is publishing non-scientific articles and how those are treated and published on the website

- Open access policy

- The journal publishing ethics and how plagiarism is handled.

- Call for papers and special issues

- In what databases the journal is indexed

- The average duration of the peer review process

68 EUR-Lex, Directive (EU) 2016/2102 of the European Parliament and of the Council of 26 October 2016 on the accessibility of the websites and mobile applications of public sector bodies, https://eur-lex.europa.eu/legalcontent/EN/TXT/?uri=uriserv:OJ.L $\quad$ 2016.327.01.0001.01.ENG\&toc=OJ:L:2016:327:TOC (Accessed March $18^{\text {th }} 2021$. 
- Links to other webpages

- Contact information is very important and should be very clear so that the journal cannot be taken as a predatory journal

A journal's website should be easily navigated . It is important that a visitor quickly and easily can find relevant information on the page. It is also very important that editors answer e-mails as quickly as possible which also include questions about the journal.

\section{Adapt the Website for Mobile Phone Use}

The website should also be adapted so it works for mobile phone viewing. If the journal only publishes the articles as pdf files, these might not be displayed correctly and will be difficult to read in a mobile phone. Usually, a mobile phone app is required in order to read a pdf file. Therefore, the article should also be available as html page i.e. plain text including any figures and tables published separately from the text and not embedded in the article text itself. These figures and tables could also be clickable in order to enlarge the size for a better view.

\section{Indexed in Databases}

Instead of using Google or Google Scholar researchers within a specific research area often use special databases which index articles within the specific research area. It is easier and quicker to find an article in a special database which indexes articles within a research area. Most of the databases have a very high and good reputation and it is important that articles are indexed in relevant databases. Most scholarly databases are multidisciplinary and cover many research disciplines such as medicine, social sciences, arts and humanities and technical science. Note that search engines only indexed webpages that are freely available i.e. no cost to access the contents. The benefit of special databases is:

- The database indexes research material within the journal research area.

- It is easy to find articles within the research area.

- It will help the journal gain its main purpose of being visible and accessible to a wide audience on the Internet.

- Being visible and accessible it will improve the journal's name as a serious and reliable source of high-quality research within the specific research area.

- It is usually easy to add limits i.e. refine the search result, sort the result according to date and relevance and sort the result after type of material such as journal articles, books, book chapters, images etc.

- Usually free from advertisement or other commercial publicity.

When choosing a database, it is also important to explore what services the database provides and that the database is established and well known within the research area and research community. Some databases only indexed abstracts with no other metadata about the article or link to the pdf file with the full text. The best choice is a database which indexes as much metadata as possible which includes the authors' names, affiliations, keywords, abstract, the entire article, DOI etc. Also find out how the database is indexing articles: by crawling the journal webpage or letting the journal do the hard work uploading metadata to the database and how often the database is updated. Most of the eminent databases require a subscription in order to access the metadata. If possible, choose an open access database that does not require a subscription. If there are no open access databases within the research topic, check 
with the University library if they subscribe to the particular database you are interested in.

Which databases the journal is indexed in will only become relevant once the journal has been online for at least 3 years and published at least 2-3 of volumes with at least 3-4 issues per year, published on a regularly basis.

There are a number of special databases specialised within a certain research area. Below is a list of the most common databases, which cover almost all research areas, which journal administration should apply to be indexed in. Some of the databases can be very difficult to become a member of and the time after submission of an application to a decision of membership or rejection can take up to two years. It is very important that a journal, on the journal's website, indicates in which databases it is indexed.

Table 1. The four most common academic databases.

\begin{tabular}{ll}
\hline Database name & Description \\
\hline$\underline{\text { EBSCO }}$ & $\begin{array}{l}\text { Multidisciplinary. EBSCO is a provider, of high-quality } \\
\text { research databases, e-journals, magazine and e-books and } \\
\text { also provides free research databases for the research } \\
\text { community. }\end{array}$ \\
\hline$\underline{\text { JSTOR }}$ & $\begin{array}{l}\text { Multidisciplinary. Articles published before 1924 in USA } \\
\text { is available for free in this database. JSTOR also offers } \\
\text { scholarships for independent researchers. }\end{array}$ \\
\hline$\underline{\text { Scopus }}$ & $\begin{array}{l}\text { Multidisciplinary. Provides academic journal rankings, } \\
\text { author profiles, and an h-index calculator }\end{array}$ \\
& $\begin{array}{l}\text { Multidisciplinary. Also called Web of Knowledge. } \\
\text { Provides journal rankings, citation indexes and author } \\
\text { profiles. Contains Conference Proceedings of high quality. }\end{array}$ \\
\hline
\end{tabular}

\section{Academic Blogging}

A blog can be used by the journal to, via an informal platform in essay format, spread and discuss the research, act as a channel for informal scientific communication within the journal's research topic, analysis of published research and commentary and the exchange of ideas. Above all a blog can be helpful building a journal's academic brand and reputation and increase the impact, visitors/readers and, of course, appeal to presumptive authors submit a manuscript to the journal.

With informal means that the research is discussed without scientific review, without the normal references and notes. Informal communication can also be oral, for example coffee breaks, lunches, conference mingle etc., where the research is discussed. The opposite is formal scientific communication that takes place through scientifically reviewed articles published in periodical scientific journals, scientific reports, documents that are archived for long-term preservation or scientifically reviewed journal. 69

Discussions on a blog should be strictly serious and not personal, although the topic being discussed might be of controversial nature. Bear in mind that a blog must be

69 Sara Kjellberg. Forskarbloggar: Vetenskaplig kommunikation och kunskapsproduktion i bloggosfären [Research blogs: Scientific communication and knowledge production in the blogosphere], Doctoral Thesis, pp. 13 and 25. Lund: Lund University, 2010. 
active along with the journal which requires some work from the editorial office. Of course, a journal could also invite other researchers within the subject area as guest bloggers. That might appeal to the research community and reach out to a broader audience and highlight the blog as a quality blog and interesting. The blog must be updated frequently. If the blog is not updated on a regular basis with high quality material, readers might lose interest and stop reading the blog.

A blog can also be used to introduce researchers in the beginning of their career, discuss their research and encourage and support them.

Note that an active blog, does not have to be e-archived at the National Library until it is ended and finally closed. 70

\section{Newsletter}

The purpose of a newsletter is to keep readers and researchers updated about what's going on by creating a special entry for newsletter subscriptions via the journal's website. The newsletter includes marketing the journal and conferences, new volumes and issues, call for papers, call for reviewers etc. It can also contain information about the editor and members of the editorial committee and their background and research. This information is especially important when changing editor and editorial staff. Upcoming events such as participation in conferences, workshops etc. can be gathered in a newsletter or alternatively get a separate entry on the journal's website. Also decide if the newsletter should be sent out on a weekly, monthly or quarterly basis. The more often the more work and too seldom, no one will probably subscribe to the newsletter.

\section{Blog or Newsletter}

If the journal has a blog, a newsletter might be unnecessary since the same content can exist in both while the content of the blog is of a more scientific nature. This does not mean both cannot co-exist: a newsletter is sent out by e-mail to subscribers while a reader of the blog has to regularly visit the blog to see if anything new is published. However, a newsletter can also inform that there are new essays on the blog to read and perhaps in advance also inform about upcoming publishing on the blog with contents that might appeal to researchers.

\section{External Links to Other Webpages}

External linking to other websites sends trackable traffic which search engines will noticed and optimising the search impact when searching on the journal name or the journal research area. This is also known as Search Engine Optimization (SEO). According to Google, external links to other sites, from your journal site to other journal sites isn't specifically a ranking factor. But it can bring value to your journal website content and that in turn can be relevant for Google in search. ${ }^{71}$ However, linking out may have other benefits. Figure 8 shows three categories such as Marketing the journal, the Visibility of the journal and finally creating Networks with other journals and researchers within the research area.

70 In Sweden an inactive blog should be delivered to the National Library of Sweden before it will be removed from the web.

${ }_{71}$ English Google Webmaster Central office-hours hangout, Youtube, https://www.youtube.com/watch?v=4FkSZIW6d48 (Accessed January 26 ${ }^{\text {th }}, 2021$ ). 


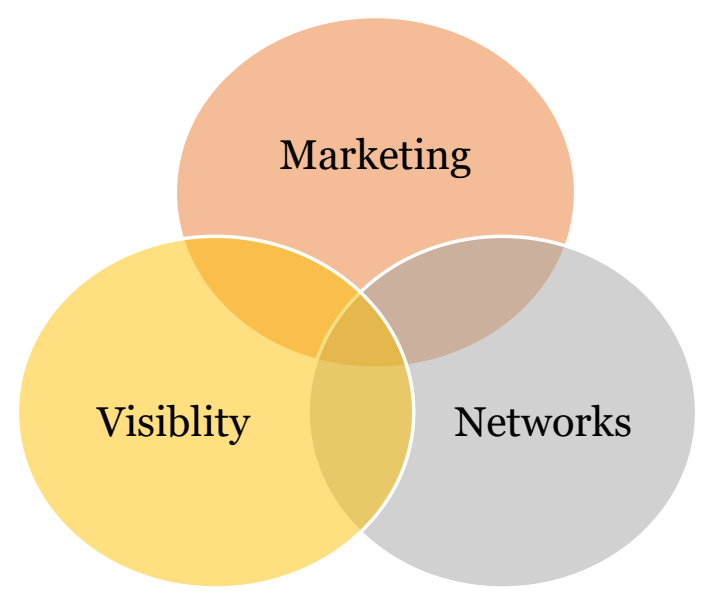

Figure 8. The relationships between the three categories.

The link page should contain links to other academic journals in the research field which may then have a link on their website to your journal. The link page may also have links to academic funding organisations that has contributed to the funding of the journal or in other way sponsored the journal economically. If the journal organises or participate in conferences within the research area, it is a great benefit linking to the conference webpage and vice versa.

\section{Visibility on the Internet}

\section{Search Engines}

An important source of information are search engines on the Internet. Their task is to index i.e. their crawlers retrieve metadata for the published articles and store data about the articles on their servers so that the metadata becomes searchable.

Metadata can be explained as information about other data. This means that one can collect information about already published data, a description of an information resource e.g. a published article. For this to work, a pre-specified and structured format must always be used. For that, a description of the information about the article is needed so that the crawler recognizes the metadata description. Metadata about an article is not publicly visible on the website itself, but metadata is embedded in the web page's code. The most widely used metadata system is Dublin Core ${ }^{72}$ and Google Scholar.

The most common search engines are Google and Google Scholar, the first being the most widely used search engine on the Internet. The difference between them is that Google Scholar focuses on scientific material published on the Internet while Google includes almost everything on the Internet.

Dublin Core has a metadata schema since the 1990 and Google Scholar has developed its own metadata schema. Open Journal System uses both systems that are published on the web page for each article, 73 which means that metadata about the article need not be manually embedded in a web page.

72 Dublin Core. Wikipedia. 2020. https://en.wikipedia.org/w/index.php?title=Dublin Core\&oldid=942242994 (Accessed April $15^{\text {th }}$ 2020).

73 Google Scholar. Inclusion Guidelines for Webmasters. 2020.

https://scholar.google.com/intl/sv/scholar/inclusion.html (Accessed April 15 ${ }^{\text {th }}$ 2020). 
An example of how metadata can look can be seen on https://doi.org/10.3384/ijal.1652-8670.18396. Right-click on the web page and select View Page Source (Applies to PC). The name may vary depending on the browser used. Dublin Core metadata starts with the element

<link rel="schema.DC" href="http://purl.org/dc/elements/1.1/" />

While the Google Scholar metadata starts with the element

$<$ meta name="gs_meta_revision" content="1.1"/>

If one as an author is not able to encode a web page with the necessary elements according to the metadata schema, then it is another opportunity to gain visibility. If a researcher has a manuscript (in pdf format) that the publishers allow to be published in advance so-called pre-print on the researcher's own personal web page, it is enough with the following metadata is available for the search engine robots to find the document:

1. The full text of the publication as a pdf file where the filename must be ended by “.pdf".

2. The title of the publication is stated as the main heading with a large font at the top of the first page of the document. No text in the page header. Google interprets the first line of a document as the title of the document.

3. The Author or authors of the article below the publication title.

4. The article i.e. the pdf file should include a list of references with the heading References or Bibliography.

Another way to increase the visibility of a particular document is to open the pdf file's properties, and in the fields fill in the metadata about the document:

- choose File and then Properties

- click the Description tab, and in the boxes type the author's name, subject and keywords

Note that Google indexes the text in the PDF file and if the article is published with two columns, Google will interpret the two columns as one column which can be displayed as nonsense text in the Google search result list when searching the article. This can, However, be avoided by ensuring the correct tab and reading order in the pdf document. To do this you need Adobe Acrobat Pro. If the article is written with two column you can control the reading order starting with the first column (left) and then the second column (right). When correcting the reading order of the columns, you can also make sure that the paragraphs, pictures, figures, tables, etc. in the columns are in the correct order. 74

\section{Social Media}

Social media has become an important instrument and platform for researchers and research students to disseminate their research results and increase their own publications' visibility. This is provided that the medium is used correctly and seriously.

Social media that are primarily effective for disseminating information for a journal are Facebook and Twitter. These two social media tools can advantageously be used

74 PDF Accessibility: Reading Order, Youtube, https://www.youtube.com/watch?v=KP5gfrdhLVs; Acrobat Library, Make your PDFs work well with Google (and other search engines), https://acrobatusers.com/tutorials/make-your-pdfs-work-well-google-and-other-searchengines/ (Accessed March 19th 2021). 
for Call for papers, inform that a new volume and issue has been published, new editorial staff or new members of the editorial committee, request reviewers for the articles, peer reviewers etc. or act as a discussion forum for researchers. Spreading information about conferences or which conferences the researchers intend to attend is another effective way of making contacts.

Twitter and Facebook feeds can tentatively be published on the first page of a journal or on a specific webpage labelled Social Media.

\section{Altmetrics}

Mentions in social media can be measured in different ways. There are several metric tools to measure citations in social medias available on the Internet. One of the methods is Altmetrics, which measures values and qualitative data that complements traditional, citation-based measurement values. Altmetrics can include peer reviews, quotes on Wikipedia, discussions on research blogs, mentions on social networks such as Facebook, Instagram and Twitter. If an author or other person writes about an article, book, book chapter etc. in social media and at the same time enters the permanent link to the publication, this is captured by Altmetrics which systematises mentions from the various social media and where in the world these mentions occur. A special logo shows the number of mentions and the number of colours in the logo shows which social media it is about (see figure 9 below). Altmetrics shows the impact of a publication in social media but also in international research networks and a map indicating where in the world a mention has been written. Including Altmetrics on the journal webpage is highly recommended.

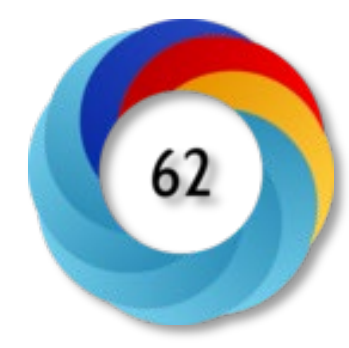

Figure 9. Altmetric with the number of mentions in social medias.

\section{Social Media and Persistent Links}

In order for Altmetrics to be able to capture mentions in social media, the persistent link, the unique identifier, must be added in connection with the mention. If a journal publishes a new issue and announces it via, for example a Tweet, the DOI or the URN:NBN must be mentioned in the message. The entire URL of the DOI or the URN:NBN link must be provided. In Altmetrics, ISBN (International Standard Book Number) can also be specified and works for books or other publications that do not have a DOI or URN: NBN but an ISBN.

\section{Scholarly networks}

Beside institutional repositories there are a number of academic social networks such as ResearchGate, Academia.edu, LinkedIn, Mendeley, SciLink, Google Scholar etc. where a researcher can share their work with the scholarly community. The major advantages with academic networks are visibility and free access (membership, free of charge, is required) to articles but also to communicate with other researchers within the same research field, sharing research result and ideas. Open access articles may also increase the citations of a researcher's own articles. The benefits of Academic network also include young researchers who are in the process of writing 
their doctoral dissertation and do not have an extensive research network for discussing their research and ideas. However, there are two major obstacles for sharing their articles with other researchers:

1. The embargo period 75 that many commercial publishers have on their recent published articles. The embargo period can of course vary depending on the journal embargo policy. For an open access journal, a research network means another channel to reach out with its publication via the authors' membership in various research networks.

2. Some commercial journals do not allow pre- or post-printing their articles in academic social networks.

These two difficulties could be minor due to the fact that several journals allow the author to publish a pre-print copy on the author's personal website. See also the headline Post-print.

Pre-print

Although most journals have an embargo period, many of them allow pre-print of the accepted manuscript, which means that the article can be published on the author's personal website or in a pre-publish repository before the article is officially published on the journal's website. A pre-print is the submitted draft/manuscript which is publicly shared before it has been peer-reviewed but often when the manuscript is accepted for publishing in a journal.

The advantage of publishing a manuscript either on the author's own website or in a pre-print archive is that the manuscript (article) becomes visible, spread worldwide and is considered as formally published, which means that the authors of an article are first to publish a research result without the article being published officially in a scientific journal. Many pre-print archives also provide a persistent link that allows the article to be cited. There are pre-print archives for almost all research areas and the table below shows the present available archives.

There is, however, pre-print has a serious disadvantage: it can undermine blinded peer review i.e. the author(s) of the article is no longer anonymous for the reviewers because the article is already published.

75 Embargo (academic publishing. Wikipedia. 2020. https://en.wikipedia.org/w/index.php?title=Embargo (academic publishing)\&oldid=951405344 (Accessed May 13th 2020); See also Gren Open Access under the headline Open Access above. 
Table 2. Pre-print archives free of charge.

\begin{tabular}{|c|c|c|}
\hline Archive Name & Homepage & Research Areas \\
\hline AgriXiv & https://osf.io/preprints/agrixiv & Agriculture \\
\hline arXiv & https://arxiv.org & $\begin{array}{l}\text { Physics, Mathematics, } \\
\text { Computer Science, } \\
\text { Quantitative Biology, } \\
\text { Quantitative Finance and } \\
\text { Statistics }\end{array}$ \\
\hline Authorea & https://www.authorea.com/ & Any research area \\
\hline $\begin{array}{l}\text { Berkeley Initiative for } \\
\text { Transparency in the } \\
\text { Social Sciences }\end{array}$ & https://osf.io/preprints/bitss & Social Sciences \\
\hline bioRxiv & http://biorxiv.org & Biology \\
\hline CERN document server & https://cds.cern.ch/collection/Preprints & Particle physics \\
\hline ChemArxiv & http://www.chemarxiv.org & Chemistry \\
\hline ChinaXiv & http://chinaxiv.org/home.htm & All research areas \\
\hline Cogprints & http://cogprints.org/ & $\begin{array}{l}\text { Psychology, Neuroscience, } \\
\text { Linguistics, Computer } \\
\text { Science, Philosophy, Biology }\end{array}$ \\
\hline CORE repository & https://mla.hcommons.org/ & Languages \\
\hline \begin{tabular}{|l|} 
Cryptology ePrint \\
Archive \\
\end{tabular} & http://eprint.iacr.org & Cryptology \\
\hline EarthArXiv & https://osf.io/preprints/eartharxiv & Earth Sciences \\
\hline e-LiS & http://eprints.rclis.org/ & $\begin{array}{l}\text { Library and information } \\
\text { science }\end{array}$ \\
\hline $\begin{array}{l}\text { Electronic Colloquium on } \\
\text { Computational } \\
\text { Complexity }\end{array}$ & https://eccc.weizmann.ac.il/eccc/ & Computer Science \\
\hline engrxiv & https://osf.io/preprints/engrxiv & Engineering \\
\hline INA-Rxiv & https://osf.io/preprints/inarxiv & All research areas \\
\hline LawArxiv & https://osf.io/preprints/lawarxiv & Law \\
\hline LIA Scholarship Archive & https://osf.io/preprints/lissa & $\begin{array}{l}\text { Librarian and information } \\
\text { science }\end{array}$ \\
\hline LingBuzz & http://ling.auf.net & Linguistics \\
\hline MindRxiv & https://mindrxiv.org & $\begin{array}{l}\text { Mind and contemplative } \\
\text { practices }\end{array}$ \\
\hline NutriXiv & https://osf.io/preprints/nutrixiv & Nutrition sciences \\
\hline OSF preprints & https://osf.io/preprints/ & All research areas \\
\hline PaleorXiv & https://osf.io/preprints/paleorxiv/ & Paleontology \\
\hline PeerJ preprints & https://peerj.com/preprints-search/ & $\begin{array}{l}\text { Biological Sciences, Medical } \\
\text { Sciences, Health Sciences and } \\
\text { Computer Sciences }\end{array}$ \\
\hline Preprints.org & http://www.preprints.org & All research areas \\
\hline PsyArXiv & https://osf.io/preprints/psyarxiv & Psychology \\
\hline RePEc & http://repec.org/ & Economics \\
\hline SocArxiv & https://osf.io/preprints/socarxiv/ & Social Sciences \\
\hline SportRxiv & https://osf.io/preprints/sportrxiv & sport science \\
\hline
\end{tabular}




\begin{tabular}{|l|l|l|}
\hline Archive Name & Homepage & Research Areas \\
\hline SSRN & https://www.ssrn.com/en/ & Social Sciences \\
\hline Therapoid & https://therapoid.net/en/preprint/ & Therapeutics \\
\hline Zenodo & https://zenodo.org/ & All research areas \\
\hline
\end{tabular}

\section{Post-print}

Post-print is also called Green Open Access, parallel publishing or self-archiving and enables the researcher to publish the publication via either the researcher's own website or the university's institutional repository. These four terms are often used to describe post-print but there is a certain difference between them. Post-Print is a draft, last version, of the article after it has been peer reviewed and accepted for publication in the journal but the article has not been formatted. ${ }^{6}$ When Selfarchiving or Parallel publishing, the author gets a copy of the already published article in order to make it open access in an institutional repository which make the article Green Open Access. 77 However, the last draft can also be used instead of the already published article.

Publications, already published in a journal via a commercial publisher, have often an embargo period 78 i.e. a limited period before the author can publish the article freely available. This, of course, if the author has not paid for open access publishing. The embargo period ranges usually from 6-12 months for Science, Technology, Engineering and Mathematics (STEM) and 12-48 months in Social Sciences and Humanities before an article can be post-published on a network or in an institutional repository. The embargo period can of course vary depending on a journal's embargo policy. When the embargo period has expired, the author can publish the publication in the institutional repository or similar non-commercial publishing platforms. Several journals allow the author to publish the article on the author's personal web page without an embargo period. Usually, the publisher's original file may not be used, but the researcher's final version of the article accepted by the publisher for publication, can instead be published. Several publishers and journals also have restrictions on parallel publishing on international research networks such as ResearchGate, Academia.net, LinkedIn, Google Scholar etc.

\section{Statistics}

Measuring the journal's statistics is a very good way to marketing a journal. There are various tools and methods available for measuring a journal's statistics. Some of the statistics can be created by journal staff by some programming and OJS has built in statistics for showing number of visitors and number of downloads of a pdf file. Below is a list of statistics that can be made visible on an article's webpage:

76 Post-Print. Wikipedia. 2021. https://en.wikipedia.org/w/index.php?title=Postprint\&oldid=1002576101 (Accessed March 20 ${ }^{\text {th }}$ 2021).

77 Self-archiving. Wikipedia. 2021. https://en.wikipedia.org/w/index.php?title=Selfarchiving\&oldid $=1002577545$ (Accessed March $20^{\text {th }} 2021$ ).

78 Embargo (academic publishing). Wikipedia. 2021.

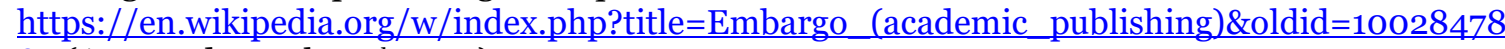
85 (Accessed March 20 ${ }^{\text {th }}$ 2021). 
- h-index:79 The h-index is a metric at author-level, that measures both the productivity and citation impact of the publications of a scientist or the scientist publications..

- citation information is a service provided by for example CrossRef, Web of Science, Scopus and Google Scholar. They extract the article citation information from thousands of journals in all research areas.

- a list of the most cited articles published as an ascending list

- Altmetrics measures of attention that a scholarly work is receiving through social media, citations, and article downloads (see the headline Altmetrics above).

- impact factor: 80 The impact factor measures the frequency in which the average article in a journal is cited in a particular year. Impact factors assess the impact of a journal, not the impact of an author's articles. If the journal is indexed in Web of Science ${ }^{81}$ (WoS), citations in WoS and the journal's impact factor can also be displayed (if the library subscribes to WoS)

- number of visitors on the article website

- number of downloads of the article's pdf file (full text) if available

- number of received, accepted, pending articles and Rejection rate

- visiting statistics from different countries

- author statistics, from which countries the authors come from

- average of the publishing process, from submitted manuscript to published article

Other important

On the journal's website, the journal's statistics should be published with information on, among other things, the number of total citations of the journal taken from CrossRef.org. This information can be dynamic by retrieving the citation directly from the CrossRef database in real time when opening the web page.

79 h-Index. Wikipedia. 2020. https://en.wikipedia.org/w/index.php?title=Hindex\&oldid $=955806892$ (Accessed May $15^{\text {th }}$ 2020).

80 Impact Factor. Wikipedia. 2020. https://en.wikipedia.org/w/index.php?title=Impact factor\&oldid=955774391 (Accessed May $15^{\text {th }}$ 2020).

81 Web of Science. Wikipedia. 2020.

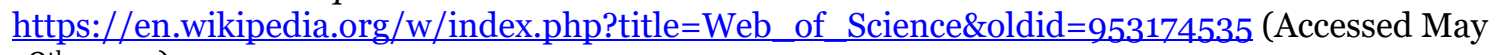
$18^{\text {th }}$ 2020). 


\section{Acknowledgement}

This essay would not be possible without help, support, guidance and comments from professionals that has experience of scholarly writing and publishing. I therefore would like to express my thanks and gratitude the following persons that has made this essay possible:

Associate Professor David Lawrence, Head of the Linköping University Library and Publishers Manager for Linköping University Electronic Press, for very relevant comments, plagiarism check, examine facts, and proofreading my English.

Professors Per Andersson and Andreas Fejes at the Department of Behavioural Sciences and Learning at Linköping University for their very valuable comments about the outline and the contents. Professor Andersson is also editor-in-chief for the journal Nordic Journal of Vocational Education and Training (NJVET) ${ }^{82}$. Professor Fejes is editor-in-chief for the journal European Journal for Research on the Education and Learning of Adults (RELA) which he also took initiative of starting the journal. Both journals are published by Linköping University Electronic Press.

A special thanks to Edvin Erdtman, Ph.D., Scientific editor at LiU E-Press, for taking his time and carefully reading the manuscript, giving insightful feedback of the contents and constructive suggestions regarding the contents of the manuscript.

The librarians Peter Fredin and Stina Degerstedt at the National Library of Sweden for their very important help how to describing the construction of URN:NBN.

82 Nordic Journal of Vocational Education and Training (NJVET), http://www.njvet.ep.liu.se/; European Journal for Research on the Education and Learning of Adults (RELA), https://www.rela.ep.liu.se/ (Accessed August 25 $5^{\text {th }}$ 2020). 


\section{References}

Acrobat Library, Make your PDFs work well with Google (and other search engines), https://acrobatusers.com/tutorials/make-your-pdfs-work-well-google-and-othersearch-engines/ (Accessed March 19th 2021) (Accessed March 19th 2021).

Article Processing Charge (APC). Wikipedia. 2020. https://en.wikipedia.org/w/index.php?title=Article processing charge\&oldid $=94$ $\underline{8486566}$ (Accessed March $19^{\text {th }}$ 2020).

arXiv.org https://arxiv.org/about (Accessed January $1^{\text {st }} 2020$ ).

Berne Convention. Wikipedia. 2020.

https://en.wikipedia.org/w/index.php?title=Berne Convention\&oldid=949417317 (Accessed April $8^{\text {th }}$ 2020).

Committee on Publication Ethics (COPE). Promoting integrity in scholarly research and its publication. 2020. https://publicationethics.org/ (Accessed July $21^{\text {st }}$ 2020).

Copyright Transfer Agreement. Wikipedia. 2020.

https://en.wikipedia.org/w/index.php?title=Copyright transfer agreement\&oldi $\underline{\mathrm{d}=934181894}$ (Accessed March 23 $3^{\text {rd } 2020 \text { ). }}$

Creative Commons. 2020 http://www.creativecommons.se/ (Accessed February 18 ${ }^{\text {th }}$ 2020).

CrossRef.org. 2020. https://www.crossref.org/ (Accessed March $1^{\text {st }}$ 2020).

CrossRef.org. Similarity Check. 2020. https://www.crossref.org/services/similaritycheck/ (Accessed March 22 ${ }^{\text {nd }}$ 2020).

CrossRef.org. Similarity Check fees. 2020.

https://www.crossref.org/fees/\#similarity-check-fees (Accessed March 22 ${ }^{\text {nd }}$ 2020).

Crossref.org. Cited-by. 2020. https://www.crossref.org/services/cited-by/ (Accessed August 17 ${ }^{\text {th }}$ 2020).

Digitala Vetenskapliga Arkivet (DiVA) About DiVA, DiVA Portal. 2020. https://info.diva-portal.org/about-diva/ (Accessed March 20 ${ }^{\text {th }}$ 2020).

Directory of Open Access Journals (DOAJ), About. 2020. https://doaj.org/about (Accessed January $25^{\text {th }}$ 2020).

Directory of Open Access Journals (DOAJ). Principles of Transparency and Best Practice in Scholarly Publishing. 2020. https://doaj.org/bestpractice (Accessed August $7^{\text {th }}$ 2020).

Dublin Core. Wikipedia. 2020. https://en.wikipedia.org/w/index.php?title=Dublin Core\&oldid=942242994 (Accessed April 15 ${ }^{\text {th }}$ 2020).

Elsevier. Sharing research data. 2020. https://www.elsevier.com/authors/authorresources/research-data (Accessed July 26th 2020).

English Google Webmaster Central office-hours hangout, Youtube, https://www.youtube.com/watch?v=4FkSZIW6d48 (Accessed January 26 ${ }^{\text {th }}$ 2021).

Embargo (academic publishing). Wikipedia. 2020.

https://en.wikipedia.org/w/index.php?title=Embargo (academic publishing)\&ol did=951405344 (Accessed May 13th 2020).

EUR-Lex, Directive (EU) 2016/2102 of the European Parliament and of the Council of 26 October 2016 on the accessibility of the websites and mobile applications of 
public sector bodies, https://eur-lex.europa.eu/legal-

content/EN/TXT/?uri=uriserv:OJ.L $\quad .2016 .327 .01 .0001 .01 . E N G \& t o c=O J: L: 2016: 327: T O C$

(Accessed March 18 2021.

European Journal for Research on the Education and Learning of Adults (RELA), https://www.rela.ep.liu.se/ (Accessed August 25th 2020).

European Union (EU). Horizon 202O. What is Horizon 2O2O. 2020. https://ec.europa.eu/programmes/horizon2020/what-horizon-2020 (Accessed April $2^{\text {nd }}$ 2020).

FORTE. Policy for Publication with Open Access. 2020.

https://forte.se/en/funding/ongoing-grants/plan-s-open-access/policypublication-open-access/ (Accessed April 12 $2^{\text {th }}$ 2020).

Freedom of the Press Act [Tryckfrihetsförordningen] (1949:105) to SFS 2018:1801.

Gajović, S., Diamond Open Access in the quest for interdisciplinarity and excellence, Croatian Medical Journal. 58(4), 2017: 261-262.

https://doi.org/10.3325/cmj.2017.58.261

General Data Protection Regulation. Wikipedia. 2020.

https://en.wikipedia.org/w/index.php?title=General Data Protection Regulatio n\&oldid=952834870 (Accessed April 26 $6^{\text {th }}$ 2020).

Google Scholar. Inclusion Guidelines for Webmasters. 2020.

https://scholar.google.com/intl/sv/scholar/inclusion.html (Accessed April 15 $5^{\text {th }}$ 2020).

Gregory, A. T. \& Denniss, A. R. Everything You Need to Know About Peer Review The Good, The Bad and The Ugly. Heart, Lung and Circulation, 28(8) 2019: 11481153. https://doi.org/10.1016/j.hlc.2019.05.171

Grudniewicz, A., Moher, D., Cobey, K. D. et al. Predatory journals: no definition, no defence, Nature, 2019, Vol. 576, 210-212, https://doi.org/10.1038/d41586-01903759-y (Accessed July 21 ${ }^{\text {st }}$ 2020).

h-index. Wikipedia. 2020. https://en.wikipedia.org/w/index.php?title=Hindex\&oldid $=955806892$ (Accessed May 15th 2020).

Haffar, S., Bazerbachi, Fateh \& Murad, M. Hassan. Peer Review Bias: A Critical Review. Mayo Clinic Proceedings, 94(4), 2019: 670-676. https://doi.org/10.1016/j.mayocp.2018.09.004.

History of the Open Access Movement. Open Access: Der freie Zugang zu wissenschaftlicher Information. 2020. https://open-access.net/en/informationon-open-access/history-of-the-open-access-movement (Accessed February $1^{\text {st }}$ 2020).

Impact Factor. Wikipedia. 2020. https://en.wikipedia.org/w/index.php?title=Impact factor\&oldid $=955774391$ (Accessed May $15^{\text {th }}$ 2020).

Institutional Repository. Wikipedia. 2020. https://en.wikipedia.org/w/index.php?title=Institutional repository\&oldid $=9511$ 93949 (Accessed April 25 $5^{\text {th }}$ 2020).

International DOI Foundation (IDF). Handbook 2. Numbering. 2020. https://www.doi.org/doi handbook/2 Numbering.html (Accessed April $3^{\text {rd }}$ 2020).

International DOI Foundation (IDF). The DOI System. 2020. https://www.doi.org/ (Accessed March 21 ${ }^{\text {st }}$ 2020). 
International DOI Foundation. Registration Agencies. 2020.

https://www.doi.org/registration agencies.html (Accessed April 11 ${ }^{\text {th }}$ 2020).

Internet Engineering Task Force, IETF. 2020 https://www.ietf.org/ (Accessed March $21^{\text {st }}$ 2020).

Ithenticate. 2020. http://www.ithenticate.com/ (Accessed Mach $22^{\text {nd }}$ 2020).

Iverson, C., AMA manual of style : a guide for authors and editors, $10^{\text {th }}$ ed. American Medical Association, Oxford University Press, 2020. ISBN: 9780190246556. https://doi.org/10.1093/jama/9780195176339.001.0001.

Jawaid, S. A. \& Jawaid, M., How to run a successful Journal. Pakistan Journal of Medical Science, 33(6), 2017: 1517-1520.

https://doi.org/10.12669/pjms.336.14097

Journal Grants. The Nordic Board for Periodicals in the Humanities and Social Sciences, https://www.aka.fi/en/nos-hs/calls/journal-grants/ (Accessed March 17th 2021).

Kjellberg, Sara. Forskarbloggar: Vetenskaplig kommunikation och kunskapsproduktion i bloggosfären [Research Blogs: Scientific communication and knowledge production in the blogosphere], Diss. Lund University, 2010. ISBN: 978-91-7473-027-2.

The LaTeX Project. LaTeX - A document preparation system. 2020.

https://www.latex-project.org/ (Accessed March 18 $8^{\text {th }}$ 2020).

Li, Y., Wu, C., Yan, E. \& Li, K. Will open access increase journal CiteScores? An empirical investigation over multiple disciplines, Plos One, 13(8), 2018: e0201885 https://doi.org/10.1371/journal.pone.0201885

Linköping University Electronic Press. 2020. http://www.ep.liu.se (Accessed June $22^{\text {nd }}$ 2020).

Legal Deposit. Wikipedia. 2020.

https://en.wikipedia.org/w/index.php?title=Legal deposit\&oldid=953072160 (Accessed April 29 ${ }^{\text {th }}$ 2020).

Lund University. Different kinds of reference styles, Lund University, https://awelu.srv.lu.se/sources-and-referencing/using-a-referencestyle/different-kinds-of-reference-styles/ (Accessed March $25^{\text {th }}$ 2021)

Masic, Izet. The Importance of Proper Citation of References in Biomedical Articles, Acta Informatica Medica, 21(3), 2013. https://doi.org/10.5455/aim.2013.21.148155 (Accessed March 26th 2021).

National Library of Sweden. E-legal deposit. 2020. https://www.kb.se/inenglish/about-us/how-we-collect-material/legal-deposit/e-legal-deposit.html (Accessed April 29 $9^{\text {th }}$ 2020).

Nählinder, J. Presentation at the course SCAIRE, Linköping University, October $25^{\text {th }}$ 2019, PowerPoint-presentation.

National Library of Sweden. 2020. https://www.kb.se/ (Accessed March $30^{\text {th }} 2020$ ).

National Library of Sweden. Legal Deposit https://www.kb.se/in-english/aboutus/how-we-collect-material/legal-deposit.html (Accessed March $2^{\text {nd }}$ 2020)

Nordic Journal of Vocational Education and Training (NJVET), http://www.njvet.ep.liu.se/ (Accessed August 25th 2020).

Nordin, J. 1766 års tryckfrihetsförordning: Bakgrund och betydelse [1766 Freedom of the Press Ordinance: Background and Significance] Stockholm: Kungliga biblioteket (2015). 
Okike, K., Hug, K. T., Kocher, M. S. \& Leopold, S. S., Single-blind vs Double-blind Peer Review in the Setting of Author Prestige, JAMA. 316(12), 2016: 1315-1316, https://doi.org/10.1001/jama.2016.11014

Open Access. Wikipedia. 2020.

https://en.wikipedia.org/w/index.php?title=Open access\&oldid=969970641 (Accessed January $1^{\text {st }}$ 2020).

Open Access Directory (OAD). Free and open-source journal management software. 2020. http://oad.simmons.edu/oadwiki/index.php?title=Free and opensource journal management software\&oldid=27461 (Accessed January $22^{\text {nd }}$ 2020)

OpenAIRE https://www.openaire.eu/ (Accessed April 12 ${ }^{\text {th }}$ 2020).

OpenAire, https://www.openaire.eu/research-data-how-to-license/ (Accessed March $18^{\text {th }}$ 2021).

Open peer review. Wikipedia. 2020.

https://en.wikipedia.org/w/index.php?title=Open peer review\&oldid $=95312074$ 5 (Accessed May $14^{\text {th }}$ 2020).

Open Researcher and Contributor ID (ORCID). 2020. https://orcid.org/ (Accessed March 25 $5^{\text {th }}$ 2020).

Open Researcher and Contributor ID (ORCID). Guidelines on the display of ORCID iDs in publications. 2020. https://orcid.org/content/journal-article-displayguidelines (Accessed April 12 ${ }^{\text {th }}$ 2020).

Open Science (Open Access). Horizon 2020. 2020. https://ec.europa.eu/programmes/horizon2020/en/h2020-section/open-scienceopen-access (Accessed April 12 ${ }^{\text {th }}$ 2020).

Parenthetical referencing. Wikipedia. 2021. https://en.wikipedia.org/w/index.php?title=Parenthetical referencing\&oldid=101 2948136 (Accessed March $25^{\text {th }}$ 2021).

PDF Accessibility: Reading Order, Youtube, https://www.youtube.com/watch?v=KP5gfrdhLVs (Accessed March 19 ${ }^{\text {th }} 2021$ ).

Peer Review. Wikipedia. 2020.

https://en.wikipedia.org/w/index.php?title=Peer review\&oldid $=954565841$ (Accessed May $5^{\text {th }}$ 2020).

Permalink. Wikipedia. 2020. https://en.wikipedia.org/w/index.php?title=Permalink\&oldid=971336719 (Accessed August 17 $7^{\text {th }}$ 2020).

Post-Print. Wikipedia. 2021.

https://en.wikipedia.org/w/index.php?title=Postprint\&oldid=1002576101 (Accessed March 20th 2021).

Public Knowledge Project (PKP). Appendix 1: DOAJ Application Guide for OJS Journals. 2020. https://docs.pkp.sfu.ca/getting-found-staying-found/en/gettingfound-appendix-1-DOAJ.

Public Knowledge Project (PKP). Open Journal Systems (OJS). 2020. https://pkp.sfu.ca/ (Accessed January $22^{\text {nd }} 2020$ ).

Public Knowledge Project. User guides, developer documentation and publishing tips for all of the Public Knowledge Project's software, 2020 https://docs.pkp.sfu.ca/. (Accessed July 17 $7^{\text {th }}$ 2020). 
Print on Demand. Wikipedia. 2020.

https://en.wikipedia.org/w/index.php?title=Print on demand\&oldid $=941742271$ (Accessed April 11 ${ }^{\text {th }}$ 2020).

References. Wikipedia, 2021.

https://en.wikipedia.org/w/index.php?title=Reference\&oldid=999564519 (Accessed March 24th 2021).

Resources for Editors of Scholarly Journals: Getting Started, The University of Kansas Libraries. 2020. https://guides.lib.ku.edu/journal editors/home. (Accessed August 22 ${ }^{\text {nd }}$ 2020)

Rodrigo, C., Zohreh Z., \& Wouter, P. The thematic orientation of publications mentioned on social media: Large-scale disciplinary comparison of social media metrics with citations, Aslib Journal of Information Management, 67(3), 2015, https://doi.org/10.1108/AJIM-12-2014-0173

Ross-Hellauer, T. What is open peer review? A systematic review, $P M C, 6(588), 2017$ : F100oRes. https://doi.org/10.12688/f10ooresearch.11369.2

Rowland, F., The peer-review process, Learned Publishing 15(4), 2002: 247-258. https://doi.org/10.1087/095315102760319206.

Self-archiving. Wikipedia. 2021. https://en.wikipedia.org/w/index.php?title=Selfarchiving\&oldid=1002577545 (Accessed March 20th 2021).

SPARC. Sponsorships for Nonprofit Scholarly \& Scientific Journals: A Guide to Defining \& Negotiating Successful Sponsorships. Release 1.0, July 2005. 2020. http://www.sparc.arl.org/sites/default/files/Sponsorship Guide.pdf (Accessed July $1^{\text {st }}$ 2020).

Sponsorships for Nonprofit Scholarly \& Scientific Journals: A Guide to Defining \& Negotiating Successful Sponsorships. Scholarly Publishing \& Academic Resources Coalition (SPARC), 2005. 2020.

http://www.sparc.arl.org/sites/default/files/Sponsorship Guide.pdf (Accessed July $1^{\text {st }}$ 2020).

Solomon, D. J. Developing Open Access Journals: A Practical Guide, 2008, ISBN: 9781843343400. Chandos Publishing. Available as a pdf file in an abbreviated version of the original edition: accessed March $19^{\text {th }} 2020$.

https://www.uib.no/sites/w3.uib.no/files/attachments/guide to developing oa journals.pdf (Accessed August $31^{\text {st }}$ 2020).

Sowards, S. W., What is Peer Review, and Does it Have a Future? Bibliothek Forschung und Praxis, 39(2), 2015. https://doi.org/10.1515/bfp-2015-0024.

Stranack, K. Starting a New Scholarly Journal in Africa. Public Knowledge Project 2008. https://pkp.sfu.ca/files/AfricaNewJournal.pdf.

Swedish Intellectual Property Office. 2020. https://www.prv.se/en/ (Accessed January $17^{\text {th }}$ 2020).

Swedish Data Protection Authority [Datainspektionen] 2020. https://www.datainspektionen.se/other-lang/ (Accessed January $17^{\text {th }} 2020$ ).

The Swedish Data Protection Authority [Datainspektionen]. General Data Protection Regulation (GDPR). 2020. https://www.datainspektionen.se/other-lang/ (Accessed January $17^{\text {th }}$ 2020).

Swedish press and broadcasting authority [Myndigheten för press radio \& tv] 2020. http://www.mprt.se/en/ (Accessed January 17 ${ }^{\text {th }}$ 2020). 
Swedish Research Council [Vetenskapsrådet]. Förslag till Nationella riktlinjer för öppen tillgång till vetenskaplig information [Proposal for National Guidelines for Open Access to Scientific Information], Vetenskapsrådets rapporter 2015.

Timmerberg, J. F. \& Wong, C. K., Thinking About Starting Your Own Academic Journal? May 21, 2019. Columbia University Irving Medical Center. 2020. https://www.cuimc.columbia.edu/news/thinking-about-starting-your-ownacademic-journal (Accessed August $31^{\text {st }}$ 2020).

Trajkovski, V. Editorial. A Comparison Between Electronic and Printed Journals. Journal for ReAttach Therapy and Developmental Diversities, 1(1) 2018: 1-6. https://doi.org/10.26407/2018JRTDD.1.1 (Accessed June 22 ${ }^{\text {nd }} 2020$ ).

UNSW Sydney, Why is Referencing Important?, UNSW Sydney. 2021, https://student.unsw.edu.au/why-referencing-important (Accessed March 24th 2021).

Web of Science. Wikipedia. 2020. https://en.wikipedia.org/w/index.php?title=Web of Science\&oldid=9531745.35 (Accessed May $18^{\text {th }}$ 2020).

Wicherts, J. M., Peer Review Quality and Transparency of the Peer-Review Process in Open Access and Subscription Journals, PLOS ONE, 11(1) 2016: e0147913. https://doi.org/10.1371/journal.pone.0147913 